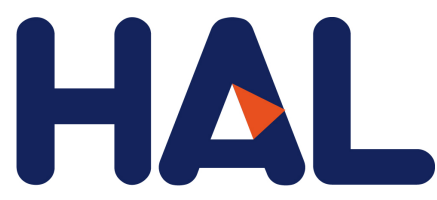

archives-ouvertes

\title{
Exo-Ocean Exploration with Deep-Sea Sensor and Platform Technologies
}

\author{
J Aguzzi, M Flexas, S Flögel, C Lo Iacono, M Tangherlini, C Costa, S Marini, \\ N Bahamon, S Martini, E Fanelli, et al.
}

\section{To cite this version:}

J Aguzzi, M Flexas, S Flögel, C Lo Iacono, M Tangherlini, et al.. Exo-Ocean Exploration with DeepSea Sensor and Platform Technologies. Astrobiology, Mary Ann Liebert, 2020, 20 (7), pp.897 - 915. 10.1089/ast.2019.2129 . hal-03203246

\section{HAL Id: hal-03203246 \\ https://hal.archives-ouvertes.fr/hal-03203246}

Submitted on 20 Apr 2021

HAL is a multi-disciplinary open access archive for the deposit and dissemination of scientific research documents, whether they are published or not. The documents may come from teaching and research institutions in France or abroad, or from public or private research centers.
L'archive ouverte pluridisciplinaire HAL, est destinée au dépôt et à la diffusion de documents scientifiques de niveau recherche, publiés ou non, émanant des établissements d'enseignement et de recherche français ou étrangers, des laboratoires publics ou privés. 


\title{
Exo-Ocean Exploration with Deep-Sea Sensor and Platform Technologies
}

\author{
J. Aguzzi, ${ }^{1,2}$ M.M. Flexas, ${ }^{3}$ S. Flögel, ${ }^{4}$ C. Lo lacono, ${ }^{1,5}$ M. Tangherlini, ${ }^{2}$ C. Costa, ${ }^{6}$ S. Marini, ${ }^{7}$ N. Bahamon, ${ }^{1}$ \\ S. Martini, ${ }^{8}$ E. Fanelli, ${ }^{2,9}$ R. Danovaro, ${ }^{2,9}$ S. Stefanni, ${ }^{2}$ L. Thomsen, ${ }^{10}$ G. Riccobene, ${ }^{11}$ M. Hildebrandt, ${ }^{12}$ \\ I. Masmitja, ${ }^{13}$ J. Del Rio, ${ }^{13}$ E.B. Clark, ${ }^{14}$ A. Branch, ${ }^{14}$ P. Weiss, ${ }^{15}$ A.T. Klesh, ${ }^{14}$ and M.P. Schodlok ${ }^{14}$
}

\begin{abstract}
One of Saturn's largest moons, Enceladus, possesses a vast extraterrestrial ocean (i.e., exo-ocean) that is increasingly becoming the hotspot of future research initiatives dedicated to the exploration of putative life. Here, a new bio-exploration concept design for Enceladus' exo-ocean is proposed, focusing on the putative presence of organisms across a wide range of sizes (i.e., from uni- to multicellular and animal-like), according to state-of-the-art sensor and robotic platforms, technologies used in terrestrial deep-sea research. In particular, we focus on combined direct and indirect life-detection capabilities, based on optoacoustic imaging and passive acoustics, as well as molecular approaches. Such biologically oriented sampling can be accompanied by concomitant geochemical and oceanographic measurements to provide data relevant to exo-ocean exploration and understanding. Finally, we describe how this multidisciplinary monitoring approach is currently enabled in terrestrial oceans through cabled (fixed) observatories and their related mobile multiparametric platforms (i.e., Autonomous Underwater and Remotely Operated Vehicles, as well as crawlers, rovers, and biomimetic robots) and how their modified design can be used for exo-ocean exploration. Key Words: Exo-ocean-EnceladusDeep-sea technology-Autonomous underwater vehicles-Crawlers-Cryobots. Astrobiology 20, xxx-Xxx.
\end{abstract}

\section{Introduction}

$\mathbf{L}$ IQUID WATER is present in the form of vast extraterrestrial oceans (i.e., exo-oceans) on various icy moons of our solar system (NASEM, 2018; Hendrix et al., 2019; Kamata et al., 2019). Five icy moons have been confirmed as ocean worlds, namely, three satellites of Jupiter (Europa, Ganymede, and Callisto) and two of Saturn (Enceladus and Titan, the latter with an exo-ocean below a thick hydrocarbon layer; Iess et al., 2012). Another four are likely to host a subsurface ocean, such as Saturn's moon Dione, Neptune's icy moon Triton, and the dwarf planet Pluto. Moreover, the dwarf planet Ceres seems to have at least a subsurface sea (Henin, 2018).

The primary conditions under which we could expect to find extant life in exo-oceans (although this hypothesis is still uncertain at this stage of scientific research) are the presence of energy sources that facilitate a non-equilibrium thermodynamic state of a marine-like medium containing abundant organic compounds (Schwieterman et al., 2018).

\footnotetext{
${ }^{1}$ Instituto de Ciencias del Mar (ICM-CSIC), Barcelona, Spain.

${ }^{2}$ Stazione Zoologica Anton Dohrn, Naples, Italy.

${ }^{3}$ California Institute of Technology, Pasadena, California, USA.

${ }^{4}$ GEOMAR Helmholtz Centre for Ocean Research Kiel, Kiel, Germany.

${ }^{5}$ National Oceanographic Center (NOC), University of Southampton, Southampton, United Kingdom.

${ }^{6}$ Consiglio per la ricerca in agricoltura e l'analisi dell'economia agraria (CREA)-Centro di ricerca Ingegneria e Trasformazioni agroalimentari - Monterotondo, Rome, Italy.

${ }^{7}$ National Research Council of Italy (CNR), Institute of Marine Sciences, La Spezia, Italy.

${ }^{8}$ Sorbonne Université, CNRS, Laboratoire d'Océanographie de Villefranche, Villefranche-sur-mer, France.

${ }^{9}$ Department of Life and Environmental Sciences, Polytechnic University of Marche, Ancona, Italy.

${ }^{10}$ Jacobs University, Bremen, Germany.

${ }^{11}$ Istituto Nazionale di Fisica Nucleare (INFN), Laboratori Nazionali del Sud, Catania, Italy.

${ }^{12}$ German Research Center for Artificial Intelligence (DFKI), Bremen, Germany.

${ }^{13}$ SARTI, Universitat Politècnica de Catalunya (UPC), Barcelona, Spain.

${ }^{14}$ Jet Propulsion Laboratory, California Institute of Technology, Pasadena, California, USA.

${ }^{15}$ COMEX, Marseille, France.
} 
Among the above-mentioned icy moons, Enceladus and Europa meet these conditions. Both host large water-based oceans in which geothermal activity is present and where life could be possible (Manga and Wang, 2007; Iess et al., 2014; Deamer and Damer, 2017; Rovira-Navarro et al., 2019). In fact, relevant geothermal activity has been imaged on both moons by the Cassini-Huygens probe as well as by the Galileo and Hubble Space Telescope space missions (Henin, 2018). Notwithstanding, the presence of organic molecules as markers for more complex compounds (e.g., amino acids and nucleotides), dissolved into a salty marine medium, has been directly indicated by the Cassini-Huygens probe of Enceladus' plumes (McKay et al., 2014; Hsu et al., 2015; Kimura and Kitadai, 2015; Mann, 2017; Postberg et al., 2018). This fact makes Enceladus the most promising site for extraterrestrial life exploration (Postberg et al., 2018).

Enceladus is $500 \mathrm{~km}$ in diameter with a gravity field of only $1.2 \%$ that of Earth (Manga and Wang, 2007). Its vast exo-ocean mechanically decouples the rocky core from the exterior ice shell (Thomas et al., 2016). The water body is kept fluid by geothermal activity in combination with tidal warming through Saturn's tidal pull forces and by ice shell thickness variations, all likely contributing to abrupt changes in water column pressure (Hussmann et al., 2006; Manga and Wang, 2007; Jansen, 2016; Saxena et al., 2018; Hemingway and Mittal, 2019; Neveu and Rhoden, 2019). Pressure changes result in active geysers, which eject water plumes into space, creating the phenomenon of cryo-

F1 volcanism (Fig. 1). Strong geothermal gradients and high pressure produce large fluxes of hot water, transported through the ice shell via cracks and crevasses (Choblet et al., 2017). Due to decompression shocks, water suddenly evaporates and freezes once it emerges into space, dropping back on the surface as snow (Běhounková et al., 2017).

Exo-ocean salinity conditions on Enceladus seem to be similar to those on Earth (Fifer et al., 2019), which would lead to a water density of approximately $1020 \mathrm{~kg} / \mathrm{m}^{3}$, similar to that of terrestrial oceans (Hemingway and Mittal, 2019). However, the average depth is much higher, being approximately between 30 and $50 \mathrm{~km}$ (Iess et al., 2014, Hemingway and Mittal, 2019). This would generate a total volume of around $40 \%$ of the mass of the moon itself (Čadek et al., 2016). Enceladus' ice shell has an average thickness of 20 $30 \mathrm{~km}$ with reduced thickness at the South Pole (Čadek et al., 2016; Lucchetti et al., 2017; Hemingway and Mittal, 2019).

Enceladus' exo-ocean seems to have been in a fluid state for a time span equivalent to that of the oceans on Earth (Choblet et al., 2017; Lunine, 2017; Jia et al., 2018), potentially allowing abiogenesis and evolution of unicellular and multicellular-like life-forms (Barge et al., 2017, 2019). Geothermal activity seems to be a component that favored the emergence of primordial life on Earth, driving its evolution in the deep sea (Baross and Hoffman, 1985; Burcar et al., 2015). Similarly, exo-ocean geothermal activity could favor the evolution of organisms with chemosynthetic metabolic pathways analogous to those documented in highly productive hydrothermal communities on Earth (e.g., Chyba and Hand, 2001; Barge and White, 2017; Seewald, 2017). During the geological history, those exo-ocean hydrothermal vent systems could have evolved into biodiversity-rich environments with chemosynthetic autonomous communities of primary producers, grazers, predators, scavengers, and remineralizing organisms (e.g., Lelièvre et al., 2018).

Unfortunately, exploration for life in Enceladus' exoocean presents technological challenges of much higher complexity than the exploration of any location in the deep sea on Earth. Instrument payloads will likely have a constraining effect on their use for the exploration of Enceladus over the next decades, although the weight of their casing can be greatly reduced compared to ocean instrumentation on Earth due to the reduced gravity on Enceladus. Moreover, the penetration of a potentially large ice shell requires tools to carve or melt tunnels on the scale of kilometers, in order to open the passage for any marine-like exploring platforms (Weiss et al., 2008; Flögel et al., 2018). Anyway, those technological efforts are already in place. Different projects such as the Enceladus Explorer (EnEx) and the Europa Explorer (EurEx) (Konstantinidis et al., 2013), as well as the Very-Deep Autonomous Laser-Powered Kilowatt-Class Yo-Yoing Robotic Ice Explorer (VALKYRIE) are presently focusing on autonomous navigation and control of robotic systems on, and especially under, exoocean ice shells.

\subsection{Objectives}

Motivated by data indicating that Enceladus' exo-ocean may host complex organic life and given the time span of its existence as a fluid body (Postberg et al., 2018), we provide a perspective for implementing its environmental and lifeoriented exploration based on available deep-sea technologies. We first describe high-priority sensors that are currently in use for marine sciences, when aiming at the characterization of pelagic and benthic seascapes, whose environmental conditions may affect life itself. Then we focus on those sensors that allow the detection of multicellular life-forms (i.e., animal-like), which is, to date, primarily carried out by imaging systems. At the same time, we also describe complementary molecular methods for indirect traceability of life (that would also allow the capability of detection of unicellular life). Later, we illustrate the different marine monitoring platforms and their assemblage into high-tech networks that could be used as test beds for exo-ocean life-detecting technologies. Ultimately, we propose a forward-looking pathway for environmental exploration of exo-oceans based on adapted versions of previously described sensor and platform technologies.

\section{Deep-Sea Sensors for Exo-Ocean Reckoning and Life Detection}

Prokaryotic-like life (i.e., unicellular) could be (theoretically) inhabiting exo-oceans (Merino et al., 2019). Traces of biological activity could then be detectable from tens of meters up to kilometers as has been accomplished on Earth's oceans with available deep-sea sensor technologies (Aguzzi et al., 2019).

At the same time, other sensors could be used to characterize exo-ocean seascapes, including circulation and bathymetry, as relevant ancillary information for describing ongoing oceanographic and geochemical processes, which may create conditions conducive to life itself. To date, a diversified group of environmental sensors are being used in a remote, synchronous, and long-lasting fashion at virtually 
FIG. 1. Enceladus is a small moon (diameter of about $500 \mathrm{~km}$ ) that became a research hotspot when the space probe Cassini-Huygens discovered evidence of cryovolcanism, including exhalations into space by geysers in 2005. (A and B) Imaging of individual jets spurting ice mixed with vapor and trace organic compounds. $(\mathbf{C}$ and $\mathbf{D})$ proposed mechanism generating observed geysers. Sources: DCode by Discovery; https://www.youtube.com/ watch?v=MjOpZrYLE1U; NASA/JPL/ Space Science Institute; https://www.jpl .nasa.gov/news/news.php?feature $=3382$. Color images are available online.
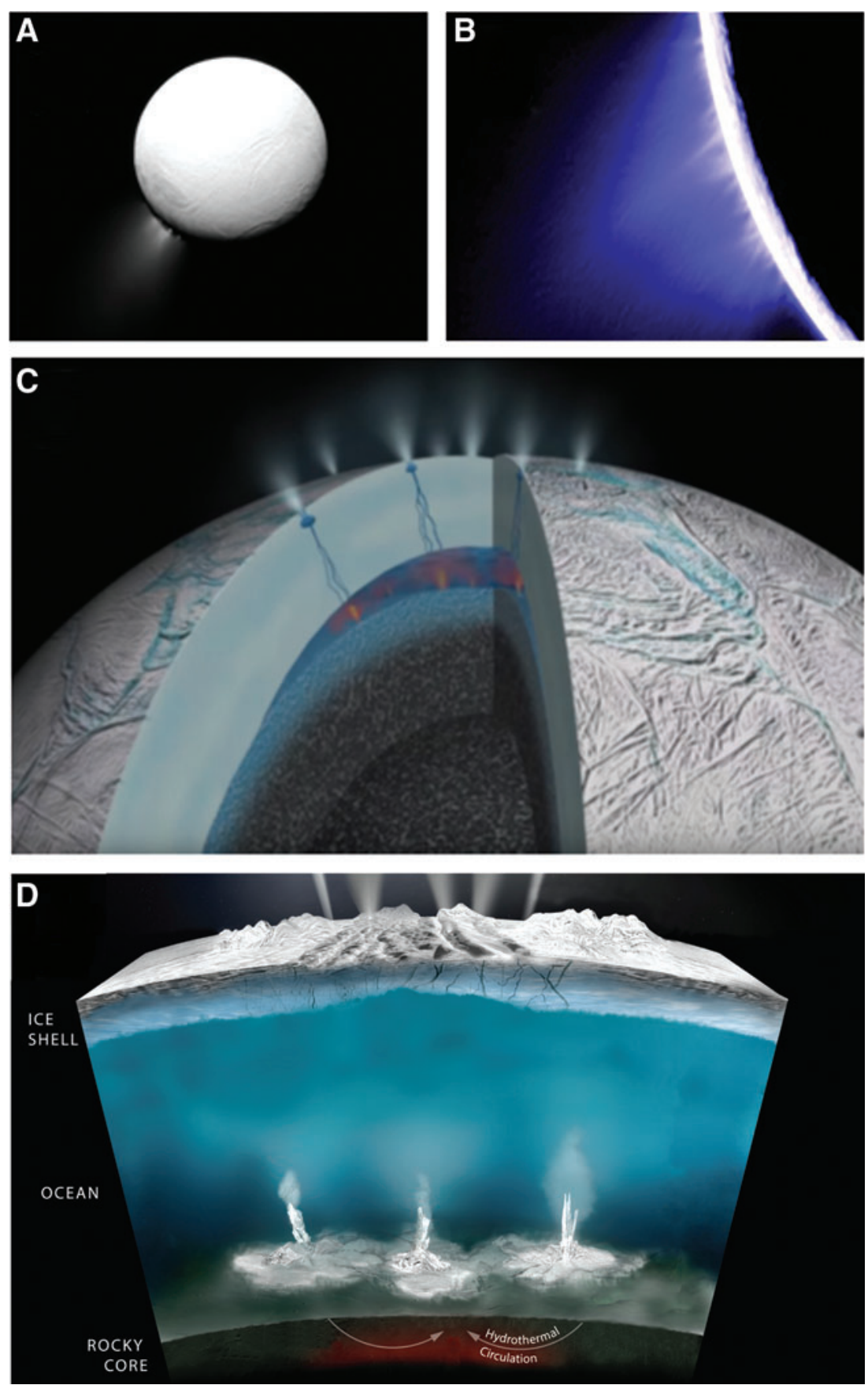

any depth of benthic and pelagic oceanic realms (Danovaro et al., 2019). Below, we describe the most relevant sensors for acquiring oceanographic and geochemical information; then we move to those sensors, providing information on T1 potential life activity (Table 1 ).

It should be noticed that current marine sensors are far from being exo-ocean flight-ready in terms of mass, robustness, autonomy, reliability, and so on. Such a development would be an engineering effort, requiring important economic sustainment, the description of which is out of the scope of this work. Moreover, the environmental knowledge needed to use these sensors in situ in an exo-ocean is not yet currently available. Therefore, due to this limitation, we describe them assuming that Enceladus' water medium conditions are similar to those present in Earth's oceans (Fifer et al., 2019; Hemingway and Mittal, 2019). In any case, such sensors are already conceived to currently operate in harsh deep-sea conditions (Ramirez-Llodra et al., 2010), including darkness, high pressure, extreme low or very high temperatures (e.g., $1-8^{\circ} \mathrm{C}$ at seabed and around $400^{\circ} \mathrm{C}$ close to hydrothermal vent emissions), and variable turbidity (Aguzzi et al., 2019).

\subsection{Oceanographic and geochemical sensors}

Enceladus' exo-ocean seascapes can be explored with different environmental sensors (Table 1). The concentration of floating particles as well as their size and organic or 


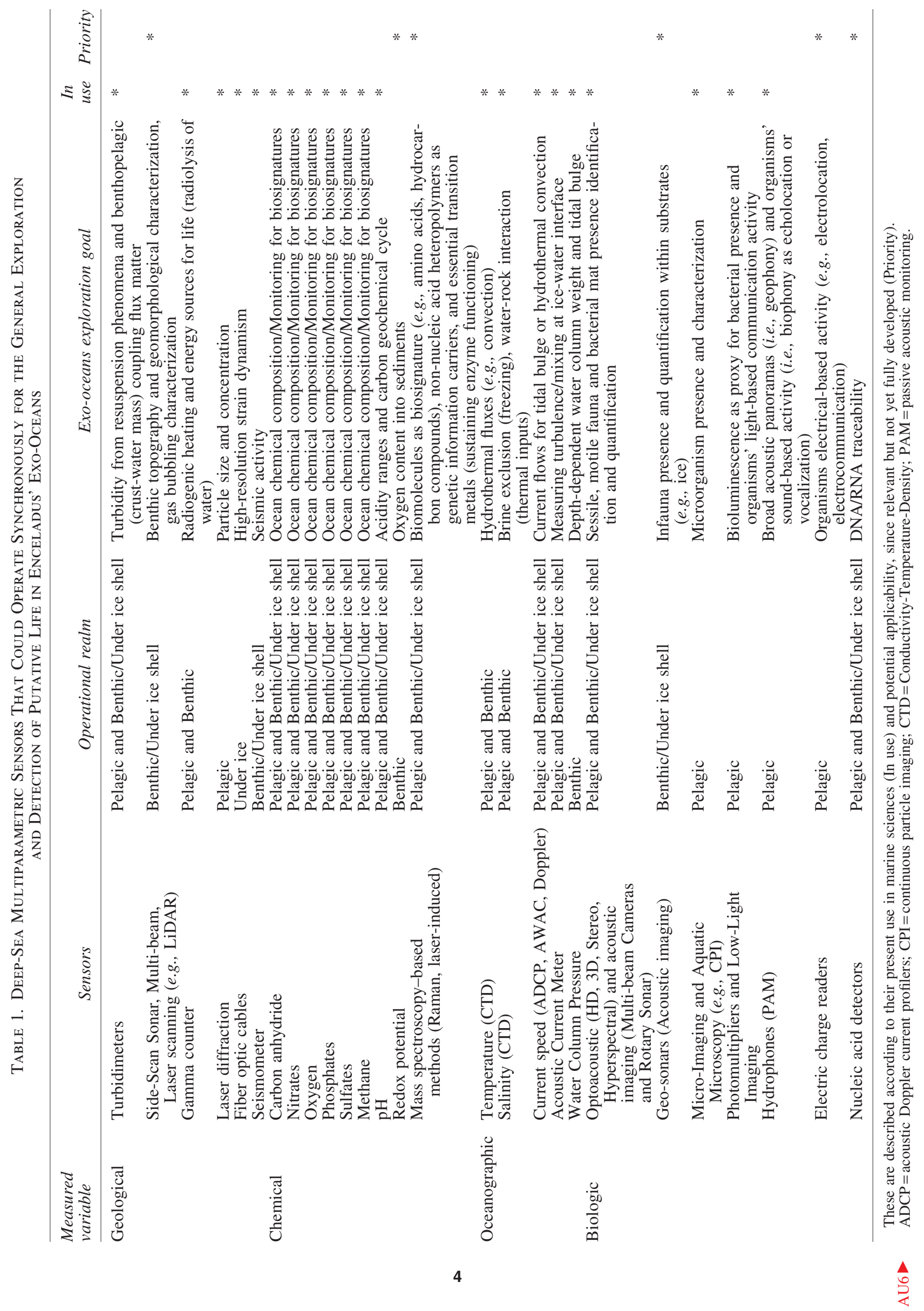


inorganic composition can be measured by light absorbance sensors, including laser diffraction and Raman spectroscopy together with a wide range of related properties (Boss et al., 2015). Floating particle size may be controlled by turbulence and by biogenic activity (e.g., marine snowlike aggregates; Turner, 2015), being the product of resuspension from deeper seafloors.

As salinity and carbon-dioxide contents of the exo-oceans seem to be similar to those on Earth (Fifer et al., 2019; Hemingway and Mittal, 2019), Conductivity-TemperatureDensity (CTD) probes as well as oxygen and $\mathrm{pH}$ sensors could also be used as relevant markers for proteins and nucleic acids stability and to set the boundaries for metabolism existence as we know it on Earth (NASEM, 2018). Nitrate, phosphate, and even methane sensors could be used as well, since they efficiently operate in environments where marked fluctuations in those dissolved gases occur at different spatiotemporal scales (e.g., Thomsen et al., 2012; Doya et al., 2015). In the case of Enceladus, measurements of dissolved methane may be of relevance in order to highlight the presence of biological chemosynthetic activity as it occurs on Mars (Formisano et al., 2004). The occurrence of essential nutrients such as nitrates and phosphates may also provide relevant hints on the distribution and productivity of life into the exo-ocean itself, and when these data are coupled with those from currents (see next section), circulation effects on potential biological productivity can be modeled (Olson et al., 2019).

\subsection{Sonars}

Enceladus' exo-ocean current regimes are presently unknown, and complex hydrodynamic seascapes may occur below the ice shell, within the water column, and near the rocky core (e.g., Rovira-Navarro et al., 2019). Scientific findings on Earth have shown that currents may deeply alter life existence, determining the concentration of life-limiting gases (e.g., oxygen minimum zones in oceans; Paulmier and Ruiz-Pino, 2009) and nutrient dispersal (Olson et al., 2019), thus conditioning the appearance of organisms as sessile or motile forms.

Active acoustic tools (e.g., acoustic Doppler current profilers, ADCP), commonly used in oceanographic studies for acquiring flow speed and direction data, could be deployed faced down, below the ice shell (Table 1) (Fifer et al., 2019; Hemingway and Mittal, 2019). For example, Aquadopp models (Nortek ${ }^{1}$ ) working at $2000 \mathrm{kHz}$ allow a maximum depth resolution of $6 \mathrm{~km}$ with an accuracy of $0.5 \mathrm{~cm} / \mathrm{s}$.

Multibeam echo sounders (MBES), based on the emission of multiple ultrasonic frequencies, are commonly used for the characterization of the seabed (Lo Iacono et al., 2008; Lurton, 2010; Lecours et al. 2016), the analysis of the water column-seabed interface, and the identification of gas plumes (Colbo et al., 2014; Innangi et al., 2016; Zhao et al. 2017). When the MBES are combined with navigation data of a moving platform (see next section), a complete characterization of Enceladus' rocky nucleus surface could be obtained (e.g., Wynn et al., 2014). In a similar way to

${ }^{1}$ https://www.nortekgroup.com/products/aquadopp-6000-m
Earth's findings, the effects of bioturbation as well as the presence of biogenic structures (actual or fossil) could be revealed by recurrent marks on the seabed surface or specific geomorphologies (Baucon et al., 2017). MBES systems could also be configured face-upward to scan the bottom of the ice shell, providing important information on its morphology and dynamics at the interface with the water (McPhail et al., 2009; Dutrieux et al., 2014a, 2014b).

Multibeam echo sounders can also be used for the quantification of animal presence in large volumes of water via the analysis of acoustic backscatter returns, when an adequate assessment of signal-to-noise ratio can be made (e.g., Briseño-Avena et al., 2015). Although preexisting knowledge on echo signature for acoustic signal crossreferencing is not yet available for exo-oceans and MBES cannot be used for the identification of any fauna, those sensors could be used to identify objects moving in the water column, thus contributing to the environmental characterization (Dunlop et al., 2018).

Finally, acoustic tomography based on sound propagation could also be employed to measure temperature, currents, and internal tides among distant and time-keeping synchronized acoustic sources (Munk et al., 1995; Finn and Rogers, 2017). Such technology could be used to derive large-scale information on exo-ocean circulation and geothermal activity. For example, acoustic tomography enabled the identification of localized convection "chimneys" in Greenland's deep sea (at $1800 \mathrm{~m}$ ) that are caused by extreme surface winter cooling (Wadhams et al., 2002). Similar techniques could be applied to detect exo-ocean geothermal fluxes.

\subsection{Optical sensors}

HD imaging is widely used in ecological exploration of $4 \mathrm{AU} 2$ Earth's deep-sea, and current tools may be used to identify the presence of fauna with sessile or motile morphological designs on icy moons, although that possibility is to date still highly uncertain (Newman, 2018). Within this context, fast-developing deep-sea imaging technologies centered on high-definition photogrammetry, stereo, hyperspectral, miniaturized cameras and low-light vision are established tools that permit assessment of the presence and activity of organisms (e.g., Kokubun et al., 2013; Bicknell et al., 2016; Corgnati et al., 2016, Marini et al., 2018a). These imaging assets could be adapted for the identification of exo-oceanic fauna in a broad range of sizes (i.e., equivalent to our prokaryotes, including bacterial mat formations, as well as micro-eukaryotes, micro- and meso-zooplankton, up to larger multicellular organisms). Those cameras require different levels of light intensity, which is a monitoring footprint whose biological effects are still under evaluation in deepsea contexts (Aguzzi et al., 2019).

\subsection{Low-light imaging technologies}

Different image-based technologies for life detection could also be used to avoid the exogenous light footprint. Such an imaging is capable of recording very low intensity emissions from organisms, as in the case of bioluminescence (see Table 1).

Environmental prerequisites that potentially favor bioluminescence existence in exo-oceans are light-deprivation 
and ecosystem stability as it occurs in Earth's deep sea. However, one should also consider the possibility that bioluminescence could be a non-existing phenomenon on Enceladus, even in the extreme case of having identified any life-form.

Bioluminescence is a ubiquitous phenomenon in environments that have been stable over large geological times on Earth (i.e., marine as compared to freshwater, where only a few bioluminescent species are known) (Haddock et al., 2010). Bioluminescence evolved independently, being present in most of the major marine phyla (Herring, 1987; Widder, 2010; Martini and Haddock, 2017; Martini et al., 2019), as well as in some bacteria (Martini et al., 2016). Bioluminescence is produced by organisms for predation, defense, and intraspecific communication (Haddock et al., 2010), and organisms can emit it after mechanical stimulation at collisions (Craig et al., 2011).

Calibrated high-resolution measurements of mechanically stimulated bioluminescence are made by the Underwater Bioluminescence Assessment Tool (UBAT), similar to a Multipurpose Bioluminescence Bathyphotometer (MBBP; Herren et al., 2005). Other systems use a stimulating grid mounted on oceanographic instruments, such as CTD, to obtain vertical pelagic profiling of bioluminescence via photomultiplying cameras (e.g., the Image Intensified Silicon Intensifier Target-ISIT; the Image Intensified Charge Couple Device for Deep-sea Research, ICDeep; e.g., Craig et al., 2015). Alternatively, other imaging systems have been developed, that is, the extreme low-light working
LuSEApher camera with photon counting capability (e.g., Barbier et al., 2012; Dominjon et al., 2012)

Other means for measuring the bioluminescence of organisms are provided by deep-sea neutrino telescopes (Martini et al., 2016; Aguzzi et al., 2017). Their mooringlike towers cover the benthopelagic dimension and are primarily instrumented with thousands of photon-detecting sensors (i.e., photomultiplier tubes, PMTs) (Fig. 2a-2c), $4 \mathrm{~F} 2$ capable of picturing the passage of neutrinos in the form of high-energy light. The main stimulation of organisms to emit light around those static structures comes on impact when swimming or as induced by turbulence behind them. The KM3NeT-Italia and ANTARES neutrino telescopes, off Capo Passero (Sicily, Western Ionian Sea) located at a depth of more than $2 \mathrm{~km}$ are an example of the threedimensionality of those infrastructures (reviewed by Aguzzi et al., 2019). Telescope moorings cover the benthopelagic dimension in the form of a cubic kilometer scale matrix of vertically extended, flexible strings which rise for hundreds of meters above the seabed (Sapienza and Riccobene, 2009).

\subsection{Acoustic imaging}

Deep-sea video monitoring of fauna is being integrated with novel acoustic (multibeam, high-frequency) cameras into efficient optoacoustic packages (Juanes, 2018) that, with an appropriate design, could be used in the search for putative life in exo-oceans (see Table 1). The Dualfrequency Identification Sonar (DIDSON) and Adaptive
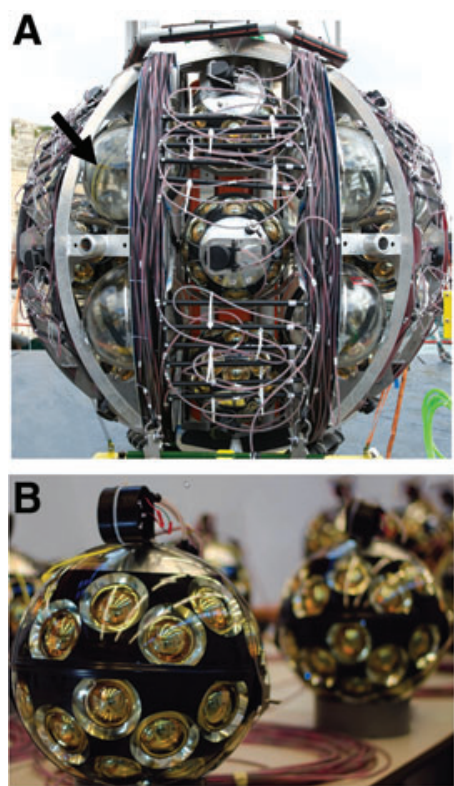
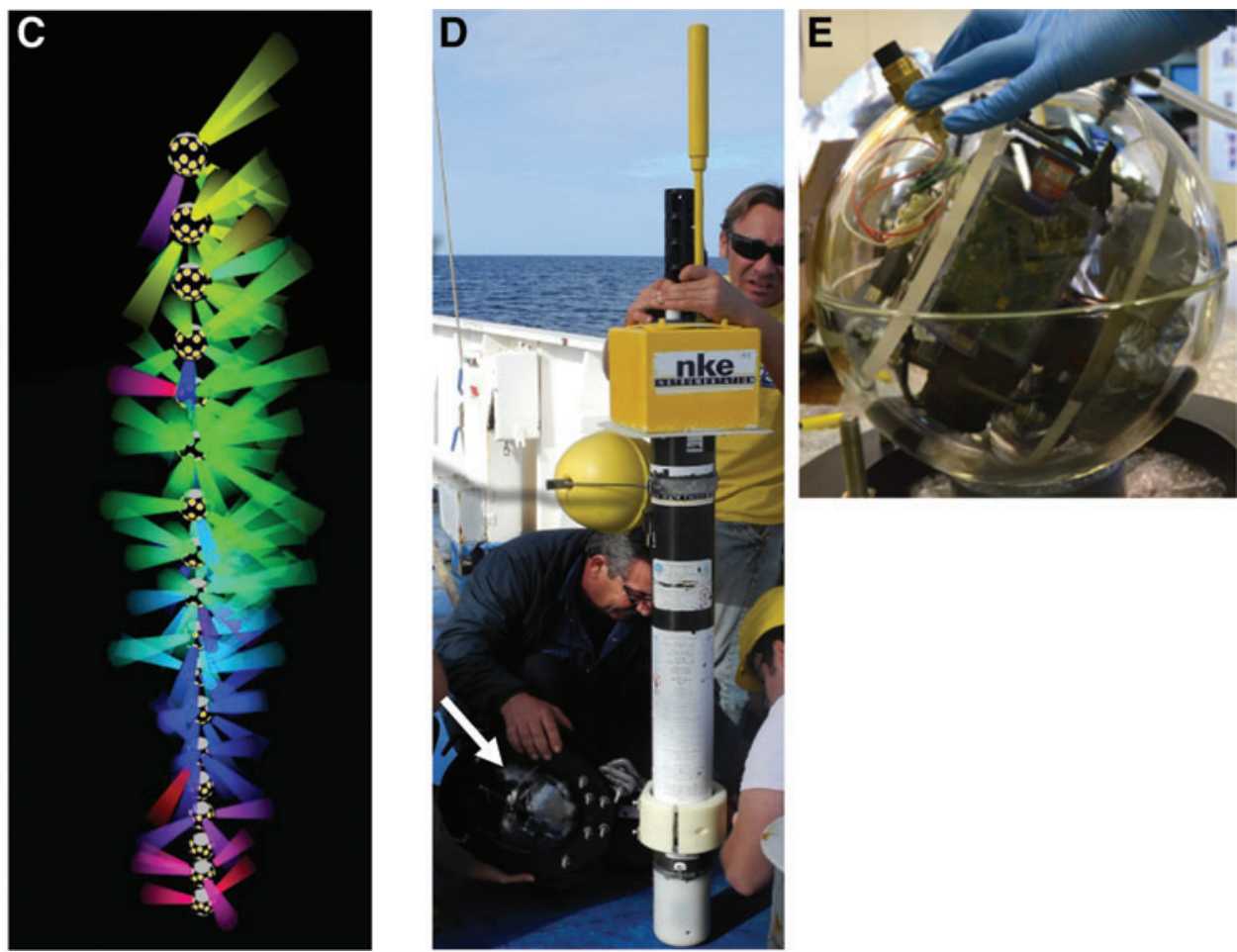

FIG. 2. Sensor devices hosted in depth-rated glass spheres. (A) Curled-up moored line of neutrino telescope spheres hosting PMTs, prior their deployment (the arrow indicates the element of the following plate, B). (B) Each single spherical unit where a set of PMTs is installed to face different angles. (C) Schematic representation of the extended moored line with all spherical units projected from the seabed, and whose PMTs are reading bioluminescence in all directions (color cones). (D) GUARD-One camera into a glass sphere connected to an Argo float (the arrow indicates the element of the following plate, E). (E) An enlargement of the glass sphere camera housing. Color images are available online. 
Resolution Imaging Sonar (ARIS) can deliver threedimensional images of organisms and map seabed features in aphotic environments, depending on organism size and ambient turbidity conditions (Aguzzi et al., 2019). That type of assets does not require light to identify and scale objects within the field of view. Unfortunately, the active emission of sound is also another monitoring footprint to be considered in unknown ecological contexts.

\subsection{Passive acoustic monitoring}

Passive acoustic monitoring (PAM) by listening hydrophones provides relevant information on biological activity based on specific sound markers (i.e., noise emission spectra) (see Table 1). In deep-sea areas on Earth, the types of organisms revealed by sound emissions cannot be identified with this sensor technology, unless we can associate their acoustic signaling with images (e.g., Archer, 2018; Mouy et al., 2018). This condition cannot be met for exo-oceans where no previous environmental knowledge exists, but the broad characterization of soundscapes and their geological and hydrographic processes are of high value, when crossed with the multiparametric data collection proposed with geochemical and oceanographic sensors. For example, the use of this technique on Earth revealed the presence of gas bubbling beyond the reach of optoacoustic imaging technologies and provided information on the extension of the phenomenon (Maksimov et al., 2016).

\subsection{Molecular-based technologies}

The detection of potential life in exo-oceans could seek environmental DNA/RNA forms (eDNA/eRNA-like) within a structural framework as known from Earth (e.g., the FISHbot initiative; Floyd, 2018) (see Table 1). Detection of nucleic acids may be measured via fluorescent dyes (indirect detection) or through nucleotide sequencing (direct detection). The former method relies on the binding of solubilized molecules with either double- or single-strand nucleic acids that interact with light at specific wavelengths. Fluorescence imaging devices (i.e., microscopy or spectrometry) are capable of detecting a wide range of dye molecules with high sensitivity, each of which shows preferential binding substrate (Suseela et al., 2018). However, false positives may occur when fluorescence dye imaging is applied to environmental samples. Inefficient staining, nonspecific binding to sample components, and autofluorescence of mineral particles under light excitation often interfere with efficient DNA/RNA detection (Li et al., 2004).

Direct sequencing of eDNA/eRNA has become a cornerstone of future marine research (Scholin et al., 2017), and the next generation of Environmental Sample Processor (ESP) on board mobile robotic platforms (see below) is contributing toward this goal (Zhang et al., 2019). A promising technology for in situ nucleic acid identification, not yet suited for the marine medium, is offered by nanopore devices (Oxford Nanopore Technologies). These devices have been successfully tested in the International Space Station (Castro-Wallace et al., 2017). Presently, the Search for Extra-Terrestrial Genomes (SETG) program is aiming to detect free nucleic acids based on nanopore sequencing technology (Carr et al., 2017).

Direct and indirect methods of detection of nucleic acids may be used for identifying environmental nucleoside al- ternative structures such as xeno-nucleic acids (eXNA; Cleaves et al., 2015). Single-Walled Carbon NanoTubes (SWCNTs) could also be used for the detection of eXNA (Gillen et al., 2018).

Other life-tracing technologies could be based on in situ mass spectrometry, which is being developed to target a wide range of organic and inorganic compounds dissolved in marine water by mobile robotic platforms (see below) (e.g., Wollschlager et al., 2016). Additionally, the use of Lab-on-a-Chip (LOC) technologies should be advanced to facilitate miniaturized time-series measurements on those platforms (Beaton et al., 2012). LOC could be used to trace metabolic products, based on the detection of free-circulating compounds through specifically designed markers, as suggested by Cassini-Huygens' recompiled information (Mathies et al., 2017).

\section{Marine Platforms and Their Networks for Exo-Ocean Exploration}

The development of fixed and autonomous mobile platforms is revolutionizing our ability to explore the deep-sea benthic and pelagic environments, acquiring information at a high resolution not achievable with vessels (Wynn et al., 2014; Aguzzi et al., 2019). A wide spectrum of oceanographic, geochemical, optic, and acoustic sensors can be installed on those platforms to explore the seafloor, the subseafloor, and the water column variability, including the potential presence of extant life (see Table 1).

Different power sources are currently used on Earthbased systems to sustain the functioning of those platforms. A continuous provision of energy can be given to fixed infrastructures by fiber optic cables or, if that is not possible, using in situ marine renewable energy resources such as water column turbines and vertical tidal oscillators, and even eolic mills and solar panels (Favali et al., 2015). In the case of exo-oceans, water turbines can be used if sufficiently strong and temporally sustained hydrodynamic forces exist. Space missions are currently using energy provision through radioactive decay (Stone et al., 2016; Cwik et al., 2019) by a Multi-Mission Radioisotope Thermoelectric Generator (MMRTG) as the core of Radioisotope Power Systems (RPS) (NASA, 2011), as in the case of the Mars Science Laboratory (Loren et al., 2013; Holgate et al., 2015). A nuclear battery efficiently converting heat into electricity and generating electrical power in smaller increments could be used for a variety of space missions, from the vacuum of the space to exo-oceanic contexts. Such a solution may last up to decades, and it may be used in future autonomous long-lasting marine and exo-oceanic exploration missions.

Acoustic or light-based modem technologies (Bai et al., 2019; Han et al., 2019; Shen et al., 2019) are being developed for communication and hence inter-operability among mobile and fixed robotic platforms to increase their working autonomy (Del Rio et al., 2011, 2018; Dunbabin and Marques, 2012; Wang et al., 2017). Those intercommunication capabilities can be used for target tracking (Masmitja et al., 2018, 2019), as navigational aids (McPhail and Pebody, 2009), or locating docking stations (Vallicrosa et al., 2014).

In this framework, this section describes the status of technological developments of marine robotic platforms with different levels of autonomy and mobility that can be 
adapted and used for exo-ocean exploration, either in standalone modes or coupled together into cooperative networks

T2 (Table 2). It is important to note that network-based redundant and prolonged data collection is of relevance to highlight spatiotemporal variations in ecological processes (Aguzzi et al., 2019).

\subsection{Cryobots}

Enceladus exo-ocean exploration should be based on penetrating robots as melting probes. The NASA-funded cryobot named VALKYRIE, developed at Stone Aerospace (Texas, USA), consists of a laser beamed down a fiber optic cable as a heat source to melt the ice, and it was successfully tested in an Alaskan glacier (Stone et al., 2014, 2018). Insights on potential pitfalls and issues related to the penetration of ice shells could be gained from the results of similar trials carried out in Antarctic subglacial lakes (Siegert, 2018). In particular, Lake Vostok might be one of the best examples to be compared to the exploration of exooceans by being separated from the rest of Earth's atmosphere by a $4 \mathrm{~km}$ thick ice layer, which had to be drilled in order to access the liquid water (Siegert et al., 2016). Unfortunately, in Lake Vostok the drill bit became damaged due to the thermal shock caused by contact with the lake water and produced an overspill of the drilling fluid (kerosene) that compromised the lake water analysis. The limits of the drilling technology used in Lake Vostok were overcome during the exploration of Lake Whillans, where a clean hot water drilling technology was used, making this lake the first successfully explored Antarctic subglacial lake (Michaud et al., 2016). Many drilling technologies are currently under investigation and under development for the exploration of the Antarctic (Talalay, 2020) subglacial lakes and Solar System worlds (Badescu and Zacny, 2018).

In relation to exo-oceans, similar melting probes could be conceived as actively "driving" through the ice, while taking and analyzing samples (e.g., Lucchetti et al., 2017). Active exploration could be performed while penetrating the ice, in order to detect remnants of life that were frozen in the ice when the shell ruptured. In particular, the VALKYRIE cryobot had an early on-board meltwater sampling system and an autonomous algorithm to command sampling (Clark et al., 2017).

\subsection{Observatories}

Multiparametric seafloor observatories, receiving power and transferring data via telecommunication cables, are currently deployed on Earth's seabed (Danovaro et al., 2017). These structures allow for highly integrated multiparametric environmental and biological data collection in benthic realms that can be extended to the pelagic ones through depth profiling yo-yo probes (i.e., performing cyclic water column ascent and descent; e.g., Fujii and Jamieson, 2016; Fanelli et al., 2019). Such platforms are open windows of the continental margin, from coastal areas to abyssal plains, to remotely study in real time life activity and its responses to environmental changes (Aguzzi et al., 2019). For example, on Earth, compacted versions of these observatories have been successfully deployed in the deep sea close to hydrothermal vents, with cable-to-shore or in a stand-alone (i.e., moored) fashion, enabling a remote and long-lasting monitoring of biological components and en- vironmental variables at hydrothermal vent sites (e.g., Colaço et al., 2011; Cuvelier et al., 2017). On Enceladus, these types of platforms may provide long-lasting Eulerian measurements of the exo-oceanic proximal water mass characteristics, alerting scientists in the case of detection of any relevant transient object.

Such fixed platforms are used to further control docked mobile platforms (see next section and Table 2). Their operational value for exo-ocean exploration resides in the necessity to deploy fixed nodes below the ice shell, capable of releasing mobile platforms, providing communications capability and power energy, permitting sampling and exploration of a larger area, while yo-yo probes move cyclically from the bottom of the ice shell through the underlying water column.

\subsection{Crawlers and rovers}

Autonomous or tethered crawlers are mobile multiparametric platforms, moving on the seabed on caterpillars (Flögel et al., 2018). They are used to expand the biological and environmental monitoring area around cabled nodes (Aguzzi et al., 2015; Thomsen et al., 2017). Crawlers are known as Internet operated vehicles (IOVs) and have the advantage of great bandwidth with the onshore station, allowing real-time navigation capability and data collection/ transmission to land via interacting web interfaces (Purser et al., 2013). Deep-sea applications of crawler technology can be found in the study of cold seeps (Chatzievangelou et al., 2016; Doya et al., 2017) and the envisaged monitoring of ecological impacts at mining (Chatzievangelou et al., 2017). For Enceladus, crawler action may increase the monitoring radius around nodes providing larger monitoring coverage.

Presently, increasing autonomy in crawler missions and data collection is being implemented through technical solutions for full cable-independence via inductive powering (i.e., recharging is based on new depth-rated lithium batteries; Brandt et al., 2016) and autonomous navigation (Wehde et al., 2019). Rover (i.e., wheeled vehicle) technology is also being implemented as a nontethered alternative to crawlers, being operative through a vessel-deployable docking station (Flögel, 2015; Wedler et al., 2015; Flögel et al., 2018). For example, the benthic mobile physiology laboratory rover has been tested in the northeastern Pacific at $4000 \mathrm{~m}$ depth and $220 \mathrm{~km}$ west of the central California coast (McGill et al., 2007).

Crawlers and rovers are of relevance for developing robotic operations practices during exo-ocean explorations, since both can move beneath the ice shells even in the presence of currents, waiting for commands from a distant control center. Reduced size/weight material and positively buoyant versions of those platforms could move upsidedown below the ice shell. Crawlers could even release floats and sink to the seafloor for upside operations. With the increase of their autonomous driving capability and multiparametric monitoring capacity, crawlers may be transformed in the future into a marine analog of the Mars Science Laboratory (Loren et al., 2013, Holgate et al., 2015), but adaptable to Enceladus.

Platforms similar to the crawler, as the Buoyant Rover for Under-Ice Exploration (BRUIE; Berisford et al., 2013), 


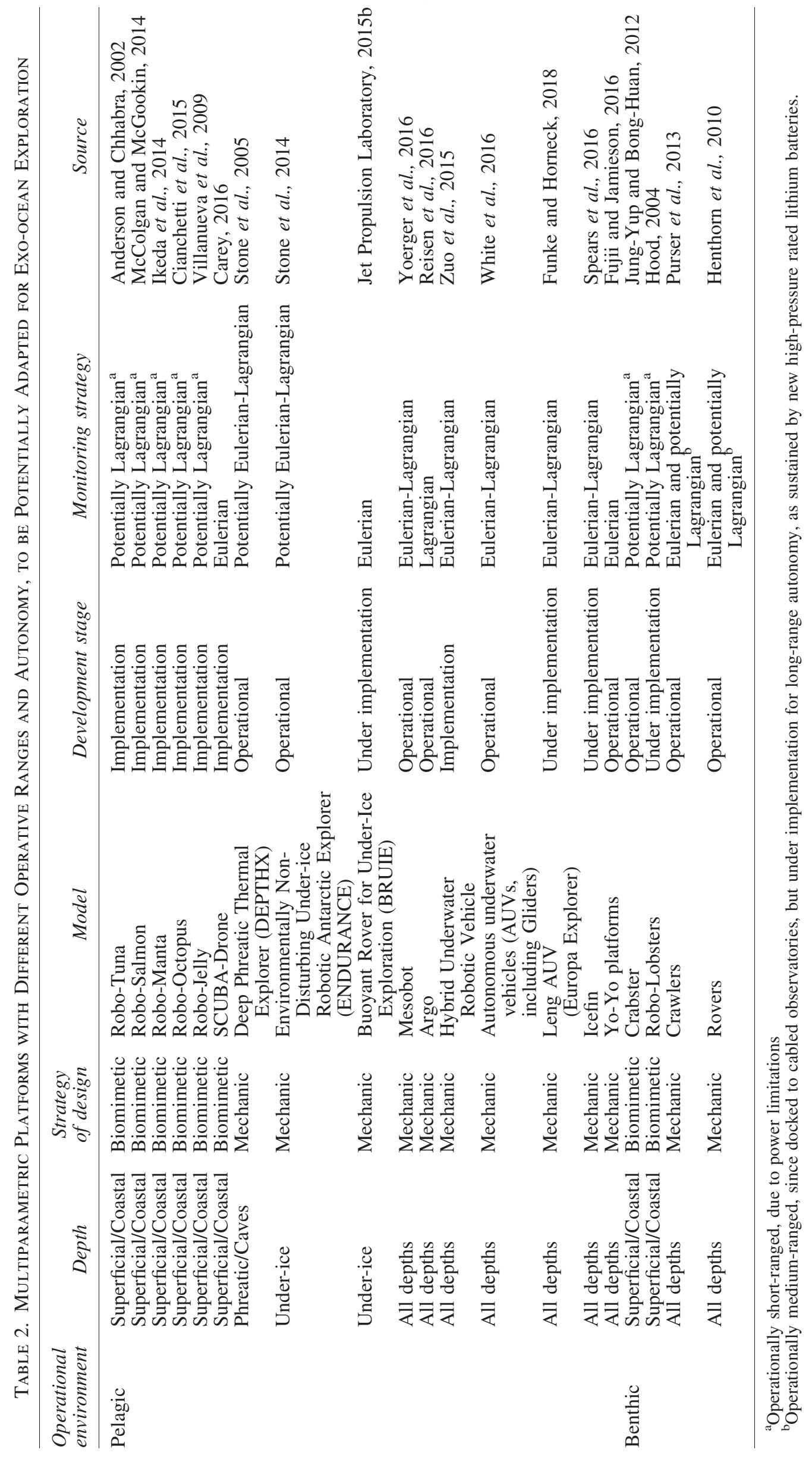


have already been tested in field deployments (Jet Propulsion Laboratory, 2015a). These positively buoyant platforms have two wheels endowed with teeth, allowing them to adhere to the ice shell bottom surface with anchoring capability at greatly reduced energy costs. These platforms have odometry-navigation capabilities and four thrusters allowing yaw control as well as the viewing angle of the camera to be independent of the vehicle's motion. Control and data transfer can be either realized by a tether or with an acoustic modem. BRUIEs are an ideal option for the exploration and monitoring of areas around fixed observatories (see the next section).

\subsection{Deep-sea autonomous underwater vehicles (AUVs)}

Autonomous underwater vehicles are of high relevance for exo-ocean exploration due to their large versatility and autonomy. A relatively wide spectrum of sensor payloads can be installed on those platforms. AUVs' geophysical seafloor acoustic sensors can be programmed to autonomously map the seafloor and image the first meters of the subseafloor (e.g., MBES; Lo Iacono et al., 2008; Lurton, 2010; Lecours et al. 2016). Such seafloor imaging can be coupled with other oceanographic and geochemical tools to explore and quantify water column variability (Morris et al. 2014; Lecours et al. 2016) (see Table 1).

Autonomous underwater vehicles are presently preprogrammed, unmanned, self-propelled vehicles that navigate for various distances possibly using dead-reckoning systems (Paull et al., 2014). Navigation systems are based on seafloor-relative velocity measurements through Doppler Velocity Log (DVL) instruments and Inertial Measurement Units (IMU). However, dead-reckoning systems need periodic adjustments in order to maintain an acceptable accuracy due to inherent errors and their accumulation over the time (Masmitja et al., 2018, 2019). Usually, AUVs emerge on the sea surface to fix GPS positions or use a combination of ultra short baseline (USBL) acoustic communication or arrays of long baseline (LBL) acoustic beacons positioned on the seafloor. Operational constraints related to an ice shell covering an exo-ocean may limit traditional navigation methods and require other approaches such as range-only single-beacon navigation (Masmitja et al. 2019).

Autonomous underwater vehicles are being coupled with cryobots (see previous crawlers and rovers section) in projects such as Subglacial Polar Ice Navigation, Descent, and Lake Exploration (SPINDLE) or Sub-Ice Marine Planetary Analog Ecosystems (SIMPLE), both funded by NASA (Stone et al., 2016). A $20 \mathrm{~km}$ range hover-capable hybrid AUV, named Autonomous Rovers/airborne-radar Transects of the Environment beneath the McMurdo Ice Shelf (ARTEMIS), developed at Stone Aerospace ${ }^{2}$, is used to perform long-range surveying of the under-ice ocean. The hybrid AUV/ROV Nereid-Under Ice (NUI; Woods Hole Oceanographic Institution) has performed near-seafloor surveys under the ice pack in the Arctic Ocean (Jakuba et al., 2018). Presently, AutoSub 3 performed the most successful underice-shelf exploration to date at the Pine Island Glacier
(McPhail et al., 2009; Jenkins et al., 2010). While these large AUVs are not suited for exo-ocean exploration, they offer platforms on which to test new technologies and autonomous methods in an analogous environment on Earth.

Autonomous underwater vehicle autonomy is presently implemented through permanent docking at cabled observatories (Wirtz et al., 2012; Hildebrandt et al., 2017). Such docking capabilities, similar to stationary ROVs presently used by the deep-sea oil industry, will allow AUVs to perform depth-rated water column ascents or descents from beneath ice shell locations (e.g., ARTEMIS docking; Kimball et al., 2018). A similar concept of remote control is represented by the Europa Underwater Probe "Icefin." This AUV platform can be considered as an autonomous and remotely controlled small multiparametric probe designed to operate below the ice shell through a tether, and could also be used in exo-ocean exploration (Spears et al., 2016).

Other innovative AUV approaches are based on novel emerging robotic technologies inspired by nature (i.e., biomimicking designs) and are of great relevance for space missions and for exo-ocean exploration. Fish-inspired solutions may be of some utility (Menon et al., 2007) due to component miniaturization (low volume/weight), robustness, mission cooperative behavior (e.g., self-repair), and long-lasting autonomy (low-energy consumption) (e.g., see Bluman et al. [2017] and Funke and Horneck [2018] for a conceptually analogous approach to the small cooperative units conceived for Mars land/atmospheric exploration). A new class of swimming robots (see Table 2) are currently being assembled with miniaturized sensor components and tested in coastal or shallow water areas (Degnarian and McCauley, 2016). In the near future, swarms of modular units (swarm-bot, or s-bot), showing some level of selfregrouping/self-repair capability and redundancy in data collection (Hunt, 2019), may prompt fine-tuned spatial coverage in Earth's deep-sea areas, to be later tested for space missions.

\subsection{Drifting platforms}

The Argo concept design ${ }^{3}$ could be implemented and adapted to explore exo-oceans. These multiparametric autonomous and freely drifting devices are being used to collect salinity and temperature in the water column down to $2000 \mathrm{~m}$ depth through consecutive cycles of ascent and descent (Riser et al., 2016). When at surface, platforms transmit data via satellite before starting a new cycle. Presently, below ice-shelf observations have been successfully carried out with floats in a prolonged and autonomous fashion (Dutrieux et al., 2018; Lee et al., 2018), also in challenging contexts of unpredictable hydrodynamic regimes (Troesch et al., 2018).

In the past 10 years, Argo platforms have been implemented with new sensors and miniaturized analyzers such as fluorescence for chlorophyll- $a$ and dissolved organic material, or oxygen, $\mathrm{pH}$, and $\mathrm{pCO}_{2}$ (Riser et al., 2016; Stanev et al., 2017). Imaging devices are getting small enough to be integrated into an Argo structure (see Fig. 2) with hardware supports capable of running artificial intelligence- 


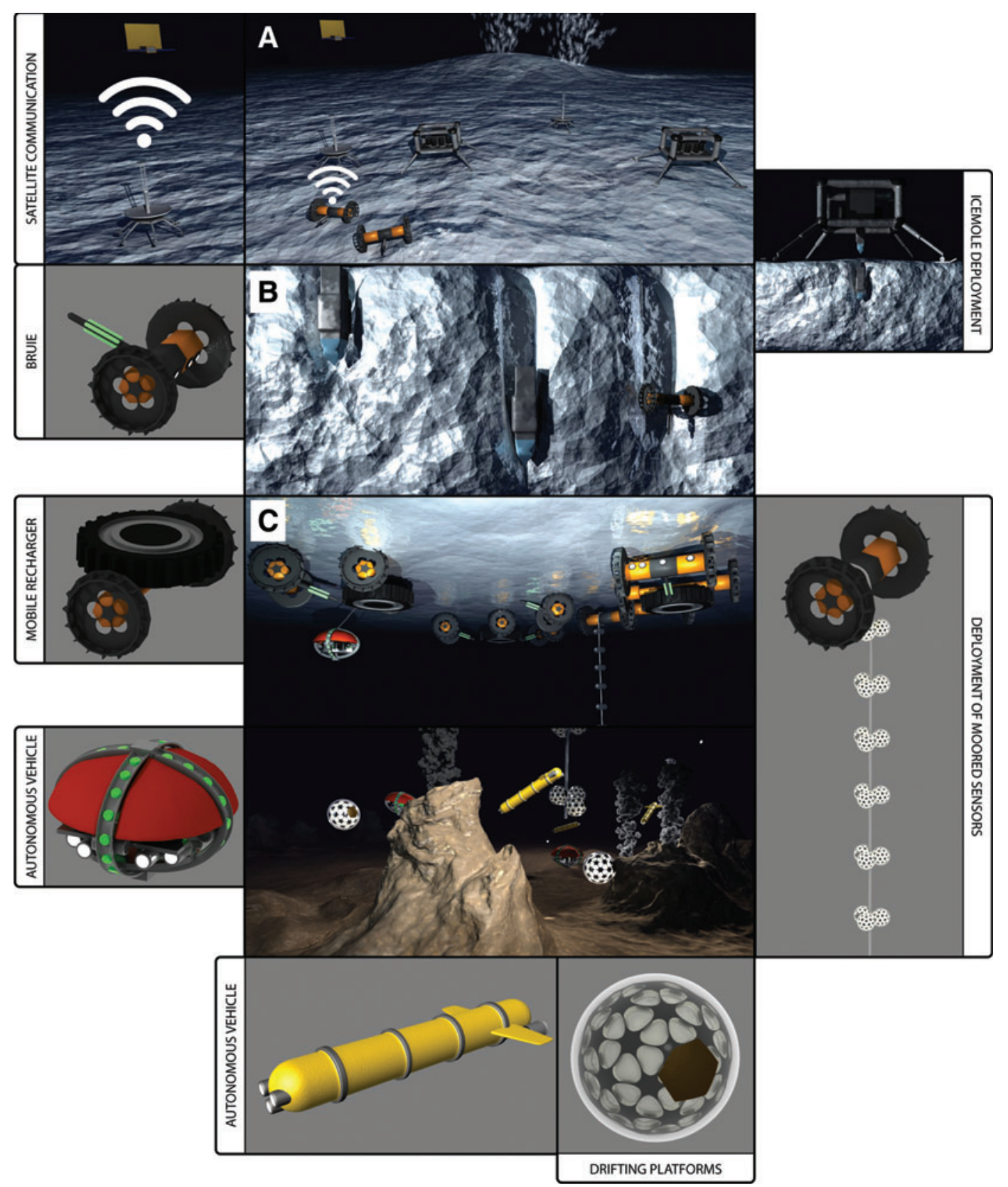

FIG. 3. The implementation of the mission concept design for Enceladus exo-ocean exploration by a network of fixed and mobile cooperative platforms. (A) Landing and platform delivery on surface. (B) Platform penetration. (C) Platform dispersion below ice, water mass reckoning, and the releasing of drifting assets. Color images are available online.

based computer vision for the detection of pelagic organisms (Marini et al., 2018a, 2018b). Those devices are being used to study a still evanescent life component of our oceans, which is represented by large aggregates (deepscattering layers) of bathymetrically displacing organisms, being hence of utility to scan large volumes of Enceladus' exo-ocean for similar purposes.

\section{A Pathway for Exo-Ocean Exploration}

A possible mission scenario can be globally drafted, according to previously presented sensor and platform technologies, following different steps described by previous authors (e.g., Cwik et al., 2019). Our concept, summarized in Fig. 3, consists of three phases: Phase 1 is landing and $4 \mathrm{~F} 3$ platform delivery on the surface (only synthetically portrayed); Phase 2 is platform penetration (already treated in the section on cryobots above); and Phase 3 is platform dispersion below ice and the release of drifting assets.

\subsection{Landing, platform delivery on surface, and data communication capability}

Enceladus exploration scenarios are based on the presence of a fixed lander system that should arrive at a safe distance from active geysers and then should release cryobots that penetrate the ice shell (Dachwald et al., 2014; Konstantinidis et al., 2015). While descending, each cryobot 
should unroll a thin cable fixed to the lander and capable of transferring power and data. That cable should resist the mechanical stress of ice closing after its passage; such a stretch and compression reliance can be achieved by a specific coating (e.g., Kevlar).

The releasing platform should remain on the surface of the icy moon in order to transmit data back from the exoocean's moon to Earth. Such a platform should be responsible for all data communication and transmission, suffering different constraints which should be carefully taken into account because of the limited navigation autonomy of mobile platforms (as described in the following sections).

The latency associated with deep space communications (79 \pm 8.3 min for Enceladus) and the communication dropout expected due to occlusion by orbital bodies (approximately $16.5 \mathrm{~h}$ for every $33 \mathrm{~h}$ on Enceladus) prevent real-time and continuous communication. The platform hosting the scientific instruments would autonomously prioritize objectives to maximize its efficiency while obeying resource and time constraints as well as completing mandatory activities, such as rendezvous for communication. To increase the effectiveness of the scientific operations, methods for semiautonomous and autonomous data collection would be designed and implemented for identifying regions of scientific interest (Zhang et al., 2012, 2016; Flexas et al., 2018), scientifically relevant features like hydrothermal vents (Branch et al. 2018), and select targets on which to perform observations (Estlin et al., 2012, Francis et al., 2017). A strategy for high-level human guidance is required to allow for refinement of autonomous behaviors based on analysis of data by scientists on Earth.

The large amount of data collected in situ cannot be entirely transmitted to Earth. Due to strict data communication constraints, it is mandatory to equip the observation platforms with software solutions able to identify and transmit only the relevant information collected. This problem happens also in deep-sea research, where solutions are provided by data science, pattern analysis, and artificial intelligence methodologies (Skiena, 2017; Aguzzi et al., 2019). Simple computer vision algorithms can be executed on board platforms' imaging asset, to identify any subject different from the water or seabed itself (Corgnati et al., 2016; Marini et al., 2018a). General approaches based on image enhancement, differencing, and background subtraction methods can be used to discard irrelevant information (Moeslund, 2012; Peters, 2017); for example, in the case of water column, ice shell, or seabed surfaces, changes in patterns would be slower with respect to traveling objects. This information can be transmitted to Earth through periodic reports and analyzed by expert scientists. Specific algorithms could then be trained to recognize and classify relevant subjects (e.g., suspended particulate, living organisms). Then the updated algorithms could be sent back to the in situ platforms to improve their effectiveness.

\subsection{Platform dispersion below ice and water mass reckoning}

Once deployed in the exo-ocean, the cryobot should act as a fixed observatory equipped with a minimal set of scientific instruments for estimating the ocean's environmental conditions. According to a positive evaluation of those conditions, the cryobots should release the BRUIEs equipped with multiparametric sensors, which would start the exo-ocean observation of the surroundings of the fixed platform. These mobile units should be equipped with wireless intercommunication capability via acoustic or light-based modem technologies (see the previous section). Data download recharging and battery could be performed by inductive pinless connection (e.g., Fonn model by Wi-Sub ${ }^{4}$; Wehde et al., 2019) among BRUIEs and/ or between the BRUIEs and the cryobot.

Those moving platforms could be endowed with highsensitivity cameras and acoustic imaging equipment (see Table 1), allowing for detection of organisms under extreme low light with a reduced footprint (i.e., potentially harmful light effects in aphotic environments). At the same time, photomultiplier tubes (PMTs) and passive acoustic technologies (PAM) should be included as well, to measure bioluminescence presence and characterize soundscapes in terms of biophony (as analogous to cetacean-like communication) and geophony (providing important data on background oceanographic and geological processes). Molecular sensors (e.g., nanopore sequencing technology) and mass spectrometry devices could complete the detection capability of any putative life, allowing organism traceability well beyond previously described sensor assets.

Some of the BRUIEs could be endowed with moored lines replicating the above-described sensor asset, to be projected into the water mass in an initial reckoning phase at unknown hydrodynamic conditions (see Fig. 3). A Eulerian picturing of water masses could be carried out with sensors hosted in physically inert and depth/pressure-rated cases (e.g., glass spheres equivalent to those used for neutrino telescope assets; Fig. 2d, 2e).

\subsection{The release of drifting platforms}

In a second stage, drifting platforms similar to Argo floats (i.e., Bio-Argo; Claustre et al., 2010) and even swarms of biomimicking robots capable of short-range swimming autonomy (see Table 2), could be released from moored projections of BRUIEs. A swarm of those walking or swimming platforms would allow local exploration of the water column or below the ice shell in areas where larger platforms could not arrive. These could deliver multidisciplinary redundant oceanographic, geochemical, and biological data within the shortest time span, to counteract any potential equipment failure under unknown oceanographic conditions (e.g., Gissinger and Petitdemange, 2019).

Once the local hydrodynamics have been characterized, BRUIE platforms may release also another group of larger cooperatively communicating mobile robotic autonomous units as AUVs (see Table 2). These AUVs would be required to expand the monitoring radius around each node. These should permit autonomous but coordinated sampling activity, constituting a locally flexible cooperative network, similar to what has been conceived for marine surveying (e.g., Thompson et al., 2017) and defense (e.g., Micro Unmanned Surface Vehicle Diving-USV from Aquabotix Technology Corporation).

\footnotetext{
${ }^{4}$ http://www.wisub.com/products/fonn
} 


\subsection{A strategy for exo-ocean platform testing}

The implementation and testing of exo-ocean lifedetection technologies could be performed in relevant deepsea environments on Earth, currently endowed with flexible monitoring benthopelagic networks of cabled fixed and mobile platforms. All these processes should involve marine scientists and aerospace engineers, who should be consulted for different mission stages of conceptualization, planning, and development. Having space agencies test their technologies at deep-sea monitoring networks will allow us to tie together the necessities for exploring remote ecosystems on Earth in order to explore extraterrestrial ones.

\section{Acknowledgments}

This work was developed within the framework of the Tecnoterra (ICM-CSIC/UPC) and the following project activities: ARIM (Autonomous Robotic sea-floor Infrastructure for benthopelagic Monitoring; MartTERA ERA-Net Cofound; PIs: J.A., S.F., and L.T.), ARCHES (Autonomous Robotic Networks to Help Modern Societies; German Helmholtz Association; PI: S.F.), RESBIO (TEC2017-87861-R; Ministerio de Ciencia, Innovación y Universidades; PIs: J.d.R., J.A.). M.M.F.'s work was partially funded by the National Aeronautics and Space Administration through grant number NNX15AG42G. A special thanks is also due to Dr. R. Sforza and Dr. G. Flati for their suggestions at writing.

A portion of this research was carried out at the Jet Propulsion Laboratory, California Institute of Technology, under a contract with the National Aeronautics and Space Administration

\section{Author Disclosure Statement}

The authors declare no competing financial interests.

\section{References}

AU3 Aguzzi, J., Company, J.B., Costa, C., Matabos, M., Azzurro, E., Mànuel, A., Menesatti, P., Sardà, F., Canals, M., Delory, E., Cline, D., Favali, P., Juniper, S.K., Furushima, Y., Fujiwara, Y., Chiesa, J.J., Marotta, L., Bahamon, N., and Priede, I.M. (2012) Challenges to assessment of benthic populations and biodiversity as a result of rhythmic behaviour: video solutions from cabled observatories. Oceanography and Marine Biology: An Annual Review 50:235-286.

Aguzzi, J., Doya, C., Tecchio, S., De Leo, F.I., Azzurro, E., Costa, C., Sbragaglia, V., Del Rio, J., Navarro, J., Ruhl, H.A., Company, J.B, Favali, P., Purser, A., Thomsen, L., and Catalán, I.A. (2015) Coastal observatories for monitoring of fish behavior and their responses to environmental changes. Rev Fish Biol Fish 25:463-483.

Aguzzi, J., Fanelli, E., Ciuffardi, T., Schirone, A., Craig, G., and the NEMO Consortium. (2017) Inertial bioluminescence rhythms at the Central Mediterranean KM3NeT deep-sea neutrino telescope. Sci Rep 7, doi:10.1038/srep44938.

Aguzzi, J., Chatzievangelou, D., Marini, S., Fanelli, E., Danovaro, R., Flögel, S., Lebris, N., Juanes, F., De Leo, F., Del Rio, J., Thomsen, L.S., Costa C., Riccobene, G., Tamburini, C., Lefevre, D., Gojak, C., Poulain, P.M., Favali, P., Griffa, A., Purser, A., Cline, D., Edigington, D., Navarro, J., and Company, J.B. (2019) New high-tech interactive and flexible networks for the future monitoring of deep-sea ecosystems. Contribution to Environmental Sciences 53:6616-6631.

Anderson, J.M. and Chhabra, N.K. (2002) Maneuvering and stability performance of a robotic tuna. Integr Comp Biol 42: 118-126.

Archer, S.K. (2018) Glass sponge reef soundscapes. J Acoust Soc Am 144, doi:10.1121/1.5067517.

Badescu, V. and Zacny, K. (2018) Outer Solar System, Springer, New York.

Bai, C., Ren, H.-P., Baptista, M.S., and Grebogi, C. (2019) Digital underwater communication with chaos. Commun Nonlinear Sci Numer Simul 73:14-24.

Barbier, R., Cajgfinger, T., Dominjon, A., and Doan, Q.T. (2012) An ebCMOS camera system for extreme low light imaging [paper ITu4C.6]. In Imaging and Applied Optics Technical Papers, Optical Society of America, Washington, DC.

Barge, L.M. and White, L.M. (2017) Experimentally testing hydrothermal vent origin of life on Enceladus and other icy/ ocean worlds. Astrobiology 17:820-833.

Barge, L.M., Branscomb, E., Brucato, J.R., Cardoso, S.S.S., Cartwright, J.H.E., Danielache, S.O., Galante, D., Kee T.P., Miguel, Y., Mojzsis, S., Robinson, K.J., Russell, M.J., Simoncini, E., and Sobron, P. (2017) Thermodynamics, disequilibrium, evolution: far-from-equilibrium geological and chemical considerations for origin-of-life research. Orig Life Evol Biosph 47:39-56.

Barge, L.M., Flores, E., Baum, M.B., VanderVedle, D.G., and Russel, M.J. (2019) Redox and pH gradients drive amino acid synthesis in iron oxyhydroxide mineral systems. Proc Natl Acad Sci USA 116:4828-4833.

Baross, J.A. and Hoffman, S.E. (1985) Submarine hydrothermal vents and associated gradient environments as sites for the origin and evolution of life. Orig Life Evol Biosph 15:327345 .

Baucon, A., Neto de Carvalho, C., Barbieri, R., Bernardini, F., Calavazzi, B., Celani, A., Felletti, F., Ferretti, A., Schonlaub, H.P., Todaro, A., and Tuniz, C. (2017) Organism-substrate interactions and astrobiology: potential, models and methods. Earth-Science Reviews 171:141-180.

Beaton, A.D., Cardwell, C.L., Thomas, R.S., Sieben, V.J., Legioret, F.-E., Waugh, E.M., Statham, P.J., Mowlem, M.C., and Morrgan, H. (2012) Lab-on-chip measurement of nitrate and nitrite for in situ analysis of natural waters. Environ Sci Technol 46:9548-9556.

Běhounková, M., Souček, O., Hron, J., and Čadek, O. (2017) Plume activity and tidal deformation on Enceladus influenced by faults and variable ice shell thickness. Astrobiology 17: 941-954.

Berisford, D.F., Leichty, J., Klesh, A., and Hand, K.P. (2013) Remote under-ice roving in Alaska with the Buoyant Rover for Under-Ice Exploration. AGU Fall Meeting Abstracts. Available online at https://ui.adsabs.harvard.edu/abs/ 2013AGUFM.C13C0684B

Bicknell, A.W., Godley, B.J., Sheehan, E.V., Votier, S.C., and Witt, M.J. (2016) Camera technology for monitoring marine biodiversity and human impact. Front Ecol Environ 14:424432.

Bluman, J.E., Kang, C.-K., Landrum, D.B., Fahimi, F., and Mesmer, B. (2017) Marsbee can a bee fly on Mars? [AIAA 2017-0328]. In 55 th American Institute of Aeronautics and Astronautics (AIAA) Aerospace Sciences Meeting, AIAA SciTech Forum, American Institute of Aeronautics and Astronautics, Reston, VA. 
Boss, E., Guidi, L., Richardson, M.J., Stemmann, L., Gardner, W., Bishop, J.K.B., Anderson, R.F., and Sherrell, R.M. (2015) Optical techniques for remote and in situ characterization of particles pertinent to GEOTRACES. Prog Oceanogr 133:43-54.

Branch, A., Xu, G., Jakuba, M.V., German, C. R., Chien, S., Kinsey, J.C., Bowen, A.D., Hand, K.P., and Seewald, J.S (2018) Autonomous nested search for hydrothermal venting. In Workshop on Planning and Robotics, International Conference on Automated Planning and Scheduling (ICAPS PlanRob 2018), Delft, the Netherlands.

Brandt, A., Gutt, J., Hildebrandt, M., Pawlowski, J., Schwendne, J., Soltwedel, T., and Thomsen, L. (2016) Cutting the umbilical: new technological perspectives in benthic deep-sea research. J Mar Sci Eng 4, doi:10.3390/jmse40 20036.

Briseño-Avena, C., Roberts, P.L.D., Franks, P.J.S., and Jaffe, J.S. (2015) ZOOPS- O2: a broadband echosounder with coordinated stereo optical imaging for observing plankton in situ. Methods in Oceanography 12:36-54.

Burcar, B.T., Barge, L.M., Trail, D., Watson, E.B., Russell, M.J., and McGown, L.B. (2015) RNA oligomerization in laboratory analogues of alkaline hydrothermal vent systems. Astrobiology 15:509-522.

Čadek, O., Tobie, G., Van Hoolst, T., Massé, M., Choblet, G., Lefèvre, A., Mitri, G., Baland, R.-M., Běhounková, M., Bourgeois, O., and Trinh, A. (2016) Enceladus's internal ocean and ice shell constrained from Cassini gravity, shape, and libration data. Geophys Res Lett 43:5653-5660.

Carey, B. (2016, April 27) Maiden voyage of Stanford's humanoid robotic diver recovers treasures from King Louis XIV's wrecked flagship. Stanford News. Available online at https://news.stanford.edu/2016/04/27/robotic-diver-recoverstreasures

Carr, C.E., Mojarro, A., Hachey, J., Saboda, K., Tani, J., Bhattaru, S.A., Smith, A., Pontefract, A., Zuber, M.T., Finney, M., Doebler, R., Brown, M., Talbot, R., Nguyen, V., Bailey, R., Ferguson, T., Church, G., and Ruvkun, G. (2017) Towards in situ sequencing for life detection. In 2017 IEEE Aerospace Conference, IEEE, Piscataway, NJ, doi:10.1109/ AERO.2017.7943896.

Castro-Wallace, S.L., Chiu, C.Y., John, K.K., Stahl, S.E., Rubins, K.H., McIntyre, A.B.R., Dworkin, J.P., Lupisella, M.L., Smith, D.J., Botkin, D.J., Stephenson, T.A., Juul, S., Turner, D.J., Izquierdo, F., Federman, S., Stryke, D., Somasekar, S., Alexander, N., Yu, G., Mason, C.E., and Burton, A.S. (2017) Nanopore DNA sequencing and genome assembly on the International Space Station. Sci Rep 7, doi:10.1038/s41598017-18364-0

Chatzievangelou, D., Doya, C., Mihály, S., Sastri, A.R., Thomsen, L., and Aguzzi, J. (2016) High-frequency patterns in the abundance of benthic species near a cold-seep-an Internet operated vehicle application. PLoS One 11, doi: 10.1371/journal.pone.0163808.

Chatzievangelou, D., Suarez, A., Aguzzi, J., Bigham, K., and Thomsen, L. (2017) Optimization of surveys with Internet Operated Deep-sea Crawlers, as an integrated tool for ocean cabled observatories: monitoring the benthic community of a methane hydrates site in Barkley Canyon (BC, Canada). $A G U$ Fall Meeting Abstracts. Available online at https://ui.adsabs .harvard.edu/abs/2017AGUFMOS21A1354C/abstract

Choblet, G., Tobie, G., Sotin, C., Běhounková, M., Čadek, O., Postberg, F., and Souček, O. (2017) Powering prolonged hydrothermal activity inside Enceladus. Nat Astron 1:841847.

Chyba, C.F. and Hand, K.P. (2001) Life without photosynthesis. Science 292:2026-2027.

Cianchetti, M., Calisti, M., Margheri, L., Kuba, M., and Laschi, C. (2015) Bioinspired locomotion and grasping in water: the soft eight-arm OCTOPUS robot. Bioinspir Biomim 10, doi: 10.1088/1748-3190/10/3/035003.

Clark, E.B., Bramall, N.E., Christner, B., Flesher, C., Harman, J., Hogan, B., and Stone, W.C. (2017) An intelligent algorithm for autonomous scientific sampling with the VALKYRIE cryobot. Int J Astrobiol 17:247-257.

Claustre, H., Bishop, J., Boss, E., Bernard, E., Berthon, J.F., Coatanoan, C., Johnson, K., Lotiker, A., Ulloa, O., Perry, M.J., D'Ortezio, F., Fanton, D., Anton, O., and Uitz, J. (2010) Bio-Optical Profiling Floats as New Observational Tools for Biogeochemical and Ecosystem Studies: Potential Synergies with Ocean Color Remote Sensing, White paper 365.16 Ko, International Ocean-Color Coordinating Group (IOCCG).

Cleaves, H.J., II, Meringer, M., and Goodwin, J. (2015) 227 Views of RNA: is RNA unique in its chemical isomer space? Astrobiology 15:538-558.

Colaço, A., Blandin, J., Cannat, M., Carval, T., Chavagnac, V., Connelly, D., Fabian, M., Ghiron, S., Goslin, J., Miranda, J.M., Reverdin, G., Sarrazin, J., Waldmann, C., and Sarradin, P.M. (2011) MoMAR-D: a technological challenge to monitor the dynamics of the Lucky Strike vent ecosystem. ICES J Mar Sci 68:416-424.

Colbo, K., Ross, T., Brown, C., and Weber, T. (2014) A review of oceanographic applications of water column data from multibeam echosounders. Estuar Coast Shelf Sci 145:41-56.

Corgnati, L., Marini, S., Mazzei, L., Ottaviani, E., Aliani, S., Conversi, A., and Griffa, A. (2016) Looking inside the ocean: toward an autonomous imaging system for monitoring gelatinous zooplankton. Sensors (Basel) 16, doi:10.3390/s16122124.

Craig, J., Jamieson, A.J., Bagley, P.M., and Priede, I.G. (2011) Naturally occurring bioluminescence on the deep sea floor. $J$ Mar Syst 88:563-567.

Craig, J., Priede, I., Aguzzi, J., Company, J.B., and Jamieson, A. (2015) Abundant bioluminescent sources of low-light intensity in the deep Mediterranean Sea and North Atlantic Ocean. Marine Biology 162:1637-1649.

Cuvelier, D., Legendre, P., Laes, A., Sarradin, P.M., and Sarrazin, J. (2017) Biological and environmental rhythms in (dark) deep-sea hydrothermal ecosystems. Biogeosciences 14:2955-2977.

Cwik, T., Zimmerman, W., and Smith, M. (2019) An architecture for a nuclear powered cryobot to access the oceans of icy worlds. In Nuclear and Emerging Technologies for Space, American Nuclear Society Topical Meeting, American Nuclear Society, La Grange Park, IL. Available online at http:// anstd.ans.org/NETS-2019-Papers/\#abstract-122

Dachwald, B., Mikucki, J., Mikucki, J., Tulaczyk, S.K., and Digel, I. (2014) IceMole: a maneuverable probe for clean in situ analysis and sampling of subsurface ice and subglacial aquatic ecosystems. Annals of Glaciology 55:14-22.

Danovaro, R., Aguzzi, J., Fanelli, E., Billet, D., Gjerde, K., Jamieson, A., Ramirez-Llodra, E., Smith, C.R., Snelgrove, P.V.R., Thomsen, L., and Van Dover, C. (2017) A new international ecosystem-based strategy for the global deep ocean. Science 355:452-454.

Danovaro, R., Fanelli, E., Aguzzi, J., Billett, D., Carugati, L., Corinaldesi, C., Dell'Anno, A., Gjerde, K., Jamieson, A.J., 
Kark, S., McClain, C., Levin, L., Levin, N., Rex, M., Ruhl, H., Smith, C.R., Snelgrove, P.V.R., Thomsen, L., Van Dover, C., AU4 and Yasuhara, M. (2019) Ecological indicators for an integrated global deep-ocean strategy. Nat Ecol Evol, in press.

Deamer, D. and Damer, B. (2017) Can life begin on Enceladus? A perspective from hydrothermal chemistry. Astrobiology 17: 834-839.

Degnarian, N. and McCauley, D. (2016, September 16) 12 robots that could make (or break) the oceans. Available online at https://www.weforum.org/agenda/2016/09/12-cutting-edge-tech nologies-that-could-save-our-oceans?utm_content=bufferf $4 \mathrm{c}$ 29\&utm_medium=social\&utm_source=plus.google.com\&utm_ campaign=buffer

Del Rio, J., Toma, D.M., O'Reilly, T.C., Bröring, A.H., Manuel, A., Headley, K.L., and Edgington, D. (2011) Interoperable data management and instrument control experiences at OBSEA. In OCEANS 2011 IEEE-Spain, IEEE, Piscataway, NJ, doi:10.1109/Oceans-Spain.2011.6003616

Del Rio, J., Toma, D.M., Martinez, E., O'Reilly, T.C., Delory, E., Pearlman, J., and Jirka, S. (2018) A sensor web architecture for integrating smart oceanographic sensors into the semantic sensor web. IEEE Journal of Oceanic Engineering 43:830-842.

Dominjon, A., Ageron, M., Barbier, R., Billault, M., Brunner, J., Cajgfinger, T., and Guérin, C. (2012) An ebCMOS camera system for marine bioluminescence observation: the $\mathrm{Lu}-$ SEApher prototype. Nuclear Instruments and Methods in Physics Research Section A: Accelerators, Spectrometers, Detectors and Associated Equipment 695:172-178.

Doya, C., Aguzzi, J., Chatzievangelou, D., Costa, C., Company, J.B. and Tunnicliffe, V. (2015) The seasonal use of smallscale space by benthic species in a transiently hypoxic area. $J$ Mar Syst 154:280-290.

Doya, C., Chatzievangelou, D., Bahamon, N., Purser, A., De Leo, F., Juniper, K., Thomsen, L., and Aguzzi, J. (2017) Seasonal monitoring of deep-sea cold-seep benthic communities using an Internet operated vehicle (IOV). PLoS One 12, doi:10.1371/journal.pone.0176917.

Dunbabin, M. and Marques, L. (2012) Robots for environmental monitoring: significant advancements and applications. IEEE Robot Autom Mag 19:24-39.

Dunlop, K.M., Jarvis, T., Benoit-Bird, K.J., Waluk, C.M., Caress, D.W., Thomas, H., and Smith, K.L., Jr. (2018) Detection and characterization of deep-sea benthopelagic animals from an autonomous underwater vehicle with a multibeam echosounder: a proof of concept and description of data-processing methods. Deep Sea Res Part 1 Oceanogr Res Pap 134:64-79.

Dutrieux, P., De Rydt, J., Jenkins, A., Holland, P.R., Ha, H.K., Lee, S.H., and Schröder, M. (2014a) Strong sensitivity of Pine Island ice-shelf melting to climatic variability. Science 343:174-178.

Dutrieux, P., Stewart, C., Jenkins, A., Nicholls, K.W., Corr, H.F.J., Rignot, E., and Steffen, K. (2014b) Basal terraces on melting ice shelves. Geophys Res Lett 41:5506-5513.

Dutrieux, P., Christianson, K.A., Lee, C., Rainville, L., Girton, J.B., Kim, T.W., and Lee, S. (2018) Seaglider and float observations beneath Dotson ice shelf, West Antarctica. AGU Fall Meeting Abstracts. Available online at https://ui.adsabs .harvard.edu/abs/2018AGUFM.C11A..01D

Estlin, T., Bornstein, B., Gaines, D., Anderson, R.C., Thompson, D., Burl, M., Castaño, R., and Judd, M. (2012) AEGIS automated science targeting for the MER Opportunity rover. ACM Trans Intell Syst Technol 3, doi:10.1145/2168752 .2168764 .
Fanelli, E., Aguzzi, J., Casotti, R., Conversano, F., D’Aiello, D., Iudicone, D., Marini, S., and Stefanni S. (2019) NEREA, the Naples Ecological REsearch for Augmented observatories: towards an end-to-end transdisciplinary approach for the study of marine ecosystems. In 2019 IMEKO TC-19 International Workshop on Metrology for the Sea.

Favali, P., Beranzoli, L., and De Santis, A. (2015) Seafloor Observatories: A New Vision of the Earth from the Abyss, Praxis, Springer, Chichester, UK.

Fifer, L., Catling, D., and Toner, J. (2019) Abundance of gases in Enceladus' ocean is a potential fuel, if life is there to consume it. In 2019 Astrobiology Science Conference.

Finn, A. and Rogers, K. (2017) An acoustic tomography technique for concurrently observing the structure of the atmosphere and water bodies. J Atmos Ocean Technol 34:617-629.

Flexas, M.M., Troesch, M.I., Chien, S., Thompson, A.F., Chu, S., Branch, A., Farrara, J.D., and Chao, Y. (2018) Autonomous sampling of ocean submesoscale fronts with ocean gliders and numerical model forecasting. J Atmos Ocean Technol 35:503-521.

Flögel, S. (2015) A new concept for high resolution benthic mapping and data acquisition: MANSIO-VIATOR. AGU Fall Meeting Abstracts. Available online at https://ui.adsabs .harvard.edu/abs/2015AGUFMIN33C1808F/abstract

Flögel, S., Ahrns, I., Nuber, C., Hildebrandt, M., Duda, A., Schwendner, J., and Wilde, D. (2018) A new deep-sea crawler system-MANSIO-VIATOR. In 2018 OCEANS MTS/IEEE Kobe Techno-Oceans (OTO), IEEE, Piscataway, NJ, doi:10.1109/OCEANSKOBE.2018.8559368.

Floyd, M.A.M., Williams, A.J., Grubisic, A., and Emerson, D. (2018) Metabolic processes preserved as biosignatures in iron-oxidizing microorganisms: implications for biosignature detection on Mars. Astrobiology 19:40-52.

Formisano, V., Atrya S., Encrenaz, T., Ignatiev, N., and Giuranna, M. (2004) Detection of methane in the atmosphere of Mars. Science 306:1758-1761.

Francis, R., Estlin, T., Doran, G., Johnstone, S., Gaines, D., Verma, V., Burl, M., Frydenvang, J., Montaño, S., Wiens, R.C., Schaffer, S., Gasnault, O., DeFlores, L., Blaney, D., and Bornstein, B. (2017) AEGIS autonomous targeting for ChemCam on Mars Science Laboratory: deployment and results of initial science team use. Science Robotics 2, doi: 10.1126/scirobotics.aan4582.

Fujii, T. and Jamieson, A.J. (2016) Fine-scale monitoring of fish movements and multiple environmental parameters around a decommissioned offshore oil platform: a pilot study in the North Sea. Ocean Engineering 126:481-487.

Funke, O. and Horneck, G. (2018) The search for signatures of life and habitability on planets and moons of our solar system. In Biological, Physical and Technical Basics of Cell Engineering, edited by G. Artmann, A. Artmann, A. Zhubanova, and I. Digel, Springer, Singapore, pp 457-481.

Gillen, A.J., Rozmysłowicz, J.K., Gigli, C., Schuergers, N., and Boghossian, A.A. (2018) Xeno nucleic acid nanosensors for enhanced stability against ion-induced perturbations. J Phys Chem Lett 9:4336-4343.

Gissinger, C. and Petitdemange, L. (2019) A magnetically driven equatorial jet in Europa's ocean. Nat Astron 3:401407.

Godø, O.R., Handegard, N.O., Browman, H., Macaulay, G.J., $<$ AU3 Kaartvedt, S., Giske, J.O.E., Huse, G., and Johnsen, E. (2014) Marine Ecosystem Acoustics (MEA): quantifying processes in the sea at the spatio-temporal scales on which they occur. ICES J Mar Sci 71:2357-2369. 
Haddock, S.H., Moline, M.A., and Case, J.F. (2010) Bioluminescence in the sea. Ann Rev Mar Sci 2:443-493.

Han, B., Zhao, W., Zheng, Y., Meng, J., Wang, T., Han, Y., Wang, W., Su, Y., Duan, T., and Xie, X. (2019) Experimental demonstration of quasi-omni-directional transmitter for underwater wireless optical communication based on blue LED array and freeform lens. Opt Commun 434:184-190.

Hemingway, D.J. and Mittal, T. (2019) Enceladus's ice shell structure as a window on internal heat production. Icarus 332: $111-131$.

Hendrix, A.R., Hurford, T.A., Barge, L.M., Bland, M.T., Bowman, J.S., Brinckerhoff, W., Buratti, B.J., Cable, M.L., Castillo-Rogez, J., Collins, G.C., Diniega, S., German, C.R., Hayes, A.G., Hoehler, T., Hosseini, S., Howett, C.J.A., McEwen, A.S., Neish, C.D., Neveu, M., Nordheim, T.A., Patterson, G.W., Patthoff, D.A., Phillips, C., Rhoden, A., Schmidt, B.E., Singer, K.N., Soderblom, J.M., and Vance, S.D. (2019) The NASA roadmap to ocean worlds. Astrobiology 19:1-27.

Henin, B. (2018) Exploring the Ocean Worlds of Our Solar System, Springer, Cham, Switzerland.

Henthorn, R.G., Hobson, B.W., Mcgill, P.R., Sherman, A.D., and Smith, K.L. (2010) Mars benthic rover: in situ rapid proto-testing on the Monterey accelerated research system. In OCEANS 2010 MTS/IEEE Seattle, IEEE, Piscataway, NJ, doi:10.1109/OCEANS.2010.5664381.

Herren, C.M., Haddock, S.H., Johnson, C., Orrico, C., Moline, M., and Case, J.F. (2005) A multiplatform bathyphotometer for fine-scale, coastal bioluminescence research. Limnol Oceanogr Methods 3:247-262.

Herring, P.J. (1987) Systematic distribution of bioluminescence in living organisms. J Biolumin Chemilumin 1:147-163.

Hildebrandt, M., Christensen, L., and Kirchner, F. (2017) Combining cameras, magnetometers and machine-learning into a close-range localization system for docking and homing [accession number 17452565]. In OCEANS 2017 - Anchorage, IEEE, Piscataway, NJ.

Holgate, T.C., Bennett, R., Hammel, T., Caillat, T., Keyser, S., and Sievers, B. (2015) Increasing the efficiency of the Multimission Radioisotope Thermoelectric Generator. Journal of Electronic Materials 44:1814-1821.

Hood, E. (2004) RoboLobsters: the beauty of biomimetics. Environ Health Perspect 112:486-489.

Hsu, H.-W., Postberg, F., Sekine, Y., Shibuya, T., Kempf, S., Horanyi, M., Juhasz, A., Altobelli, N., Suzuki, K., Masaki, Y., Kuwatani, T., Tachibana, S., Sirono, S., MoragasKlostermeyer, G., and Srama, R. (2015) Ongoing hydrothermal activities within Enceladus. Nature 519:207-210.

Hunt, E. (2019, March 27) The social animals that are inspiring new behaviors for robot swarms. The Conversation. Available online at https://theconversation.com/the-social-animalsthat-are-inspiring-new-behaviors-for-robot-swarms-113584

Hussmann, H., Sohl, F., and Spohn, T. (2006) Subsurface oceans and deep interiors of medium-sized outer planet satellites and large trans-Neptunian objects. Icarus 185:258-273.

Iess, L., Jacobson, R.A., Ducci, M., Stevenson, D.J., Lunine, J.I., Armstrong, J.W., Asmar, S.W., Racioppa, P., Rappaport, N.J., and Tortora, P. (2012) The tides of Titan. Science 377:457-459.

Iess, L., Stevenson, D.J., Parisi, M., Hemingway, D., Jacobson, R.A., Lunine, J.I., Nimmo, F., Armstrong, J.W., Asmar, S.W., Ducci, M., and Tortora, P. (2014) The gravity field and interior structure of Enceladus. Science 344:78-80.

Ikeda, M., Hkasa, S., Watanabe, A., and Nagai, I. (2014) Motion analysis of a manta robot for underwater exploration by propulsive experiments and the design of central pattern generator. International Journal of Automation Technology 22:231-237.

Innangi, S., Bonanno, A., Tonielli, R., Gerlotto, F., Innangi, M., and Mazzola, S. (2016) High resolution 3-D shapes of fish schools: a new method to use the water column backscatter from hydrographic multibeam echo sounders. Appl Acoust 111:148-160.

Li, Y., Dick W.A., and Tuovinen, O.H. (2004) Fluorescence microscopy for visualization of soil microorganisms: a review. Biol Fertil Soils 39:301-311.

Loren, J., Moreno, V., and Zimmerman, R. (2013) The F1 Multi-Mission Radioisotope Thermoelectric Generator (MMRTG): a power subsystem enabler for the Mars Science Laboratory (MSL) mission [paper 6810]. In Nuclear and Emerging Technologies for Space 2013 (NETS 2013), American Nuclear Society, La Grange Park, IL.

Jakuba, M.V., German, C.R., Bowen, A.D., Whitcomb, L.L., Hand, K., Branch, A., Chien, S., and McFarland, C. (2018) Teleoperation and robotics under ice: implications for planetary exploration. In 2018 IEEE Aerospace Conference, IEEE, Piscataway, NJ, doi:10.1109/AERO.2018.8396587.

Jansen, M.F. (2016) The turbulent circulation of a snowball Earth ocean. J Phys Oceanogr 46:1917-1933.

Jenkins, A., Dutrieux, P., Jacobs, S.S., McPhail, S.D., Perrett, J.R., Webb, A.T., and White, D. (2010) Observations beneath Pine Island Glacier in West Antarctica and implications for its retreat. Nat Geosci 3:468-472.

Jet Propulsion Laboratory. (2015a, June 25) Under-ice rover chills with fish at aquatic exhibit. JPL News. Available online at https://www.jpl.nasa.gov/news/news.php? feature $=4640$

Jet Propulsion Laboratory. (2015b, September 22) Buoyant Rover for Under Ice Exploration (BRUIE). JPL News. Available online at https://www.jpl.nasa.gov/video/details.php?id=1402

Jia, X., Kivelson, M.G., Khurana, K.K., and Kurth, W.S. (2018) Evidence of a plume on Europa from Galileo magnetic and plasma wave signatures. Nat Astron 2:459-464.

Juanes, F. (2018) Visual and acoustic sensors for early detection of biological invasions: current uses and future potential. $J$ Nat Conserv 42:7-11.

Jung-Yup, K. and Bong-Huan, J. (2012) Design of six-legged walking robot, Little Crabster for underwater walking and operation. Adv Robot 28:77-89.

Kamata, S., Nimmo, F., Sekine, Y., Kuramoto, K., Noguchi, N., Kimura, J., and Tani, A. (2019) Pluto's ocean is capped and insulated by gas hydrates. Nat Geosci 12:407-410.

Kimball, P.W., Clark, E.B., Scully, M., Richmond, K., Flesher, C., Lindzey, L.E., Harman, J., Huffstutler, K., Lawrence, J., Lelievre, S., Moor, J., Pease, B., Siegel, V., Winslow, L., Blankenship, D.D., Doran, P., Kim, S., Schmidt, B.E., and Strone, W.C. (2018) The ARTEMIS under-ice AUV docking system. J Field Robot 35:299-308.

Kimura, J. and Kitadai, N. (2015) Polymerization of building blocks of life on Europa and other icy moons. Astrobiology 15:430-441.

Kokubun, N., Kim, J.H., and Takahashi, A. (2013) Proximity of krill and salps in an Antarctic coastal ecosystem: evidence from penguin-mounted cameras. Polar Biol 36:1857-1864.

Konstantinidis, K., Flores Martinez, C.L., Dachwald, B., Ohndorf, A., Dykta, P., Bowitz, P., Rudolph, M., Digel, I., Kowalski, J., Voigt, K., and Förstner, R. (2015) A lander mission to probe subglacial water on Saturn's moon Enceladus for life. Acta Astronaut 106:63-89.

Lecours, V., Dolan, M.F.J., Micallef, A., and Lucieer, V.L. (2016) A review of marine geomorphometry, the quantitative study of the seafloor. Hydrol Earth Syst Sci 20:3207-3244. 
Lee, C., Rainville, L., Gobat, J.I., Girton, J.B., Dutrieux, P., Christianson, K.A., and Lee, S.H. (2018) Sustained, autonomous observations beneath ice shelves. AGU Fall Meeting Abstracts. Available online at https://ui.adsabs.harvard.edu/ abs/2018AGUFM.C21C1353L

Lelièvre, Y., Sarrazin, J., Marticorena, J., Schaal, G., Day, T., Legendre, P., Hourdez, H., and Matabos, M. (2018) Biodiversity and trophic ecology of hydrothermal vent fauna associated with tubeworm assemblages on the Juan de Fuca Ridge. Biogeosciences 15:2639-2647.

AU3 Liu, J., Wang, Z., Peng, Z., Cui, J., and Fiondella, L. (2014) Suave: swarm underwater autonomous vehicle localization. INFOCOM, IEEE Computer and Communications Societies, IEEE Annual Joint Conference, IEEE, Piscataway, NJ, doi: 10.1109/INFOCOM.2014.6847925.

Lo Iacono, C., García, E., Diez Tagarró, S., Bozzano, G., Ximena, M., Dañobeitia, J.J., and Alonso, B. (2008) Seafloor characterization and backscatter variability of the Almería Margin (Alboran Sea, SW Mediterranean) based on highresolution acoustic data. Mar Geol 250:1-18.

Lucchetti, A., Pozzobon, R., Mazzarini, F., Cremonese, G., and Massironi, M. (2017) Brittle ice shell thickness of Enceladus from fracture distribution analysis. Icarus 297:252-264.

Lunine, J.I. (2017) Ocean worlds exploration. Acta Astronaut 131:123-130.

Lurton, X. (2010) An Introduction to Underwater Acoustics: Principles and Application, Springer, Berlin.

Maksimov, A.O., Burov, B.A., Salomatin, A.S., and Chernykh, D.V. (2016) Sounds of undersea gas leaks. In Underwater Acoustics and Ocean Dynamics, edited by L. Zhou, W. Xu, Q. Cheng, and H. Zhao, Springer, Singapore.

Manga, M. and Wang, C.-Y. (2007) Pressurized oceans and the eruption of liquid water on Europa and Enceladus. Geophys Res Lett 34:L07202.

Mann, A. (2017) Inner workings: icy ocean worlds offer chances to find life. Proc Natl Acad Sci USA 114:4566-4568.

Marini, M., Corgnati, L., Mantovani, C., Bastianini, M., Ottaviani, E., Fanelli, E., Aguzzi, J., Griffa, A., and Poulain, P.M. (2018a) Automated estimate of fish abundance through the autonomous imaging device GUARD1. Journal of Measurement 126:72-75.

Marini, S., Fanelli, E., Sbragaglia, V., Azzurro, E., Del Rio, J., and Aguzzi, J. (2018b) Tracking fish abundance by underwater image recognition: a real world case. Sci Rep 8, doi: 10.1038/s41598-018-32089-8.

Martini, S. and Haddock, S.H.D. (2017) Quantification of bioluminescence from the surface to the deep sea demonstrates its predominance as an ecological trait. Sci Rep 7, doi: $10.1038 /$ srep45750.

Martini, S., Michotey, V., Casalot, L., Bonin, P., Guasco, S., Garel, M., and Tamburini, C. (2016) Bacteria as part of bioluminescence emission at the deep ANTARES station (North-Western Mediterranean Sea) during a one-year survey. Deep Sea Res Part 1 Oceanogr Res Pap 116:33-40.

Martini, S., Haddock, S.H.D., Mallefet, J., and Kuhnz, L. (2019) Distribution and quantification of bioluminescence as an ecological trait in the deep sea benthos. Sci Rep 7, doi: 10.1038/s41598-019-50961-z.

Masmitja, I., Gomariz, S., Del-Rio, J., Kieft, B., O’Reilly, T., Bouvet, P.-J., and Aguzzi, J. (2018) Optimal path shape for range-only underwater target localization using a Wave Glider. Int J Rob Res 37:1447-1462.

Masmitja, I., Gomariz, S., Del-Rio, J., Kieft, B., O’Reilly, T., Bouvet, P.-J., and Aguzzi, J. (2019) Range-only single- beacon tracking of underwater targets from an autonomous vehicle: from theory to practice. IEEE Access 7, doi:10.1109/ ACCESS.2019.2924722.

Mathies, R.A., Rauz, M.E., Kim, J., Stockton, A.M., Turin, P., and Butterworth, A. (2017) Feasibility of detecting bioorganic compounds in Enceladus plumes with the Enceladus Organic Analyzer. Astrobiology 17:902-912.

McColgan, J. and McGookin, E.W. (2014) Coordination of a school of robotic fish using nearest neighbour principles. In OCEANS 2014 - TAIPEI, IEEE, Piscataway, NJ, doi:10.1109/ OCEANS-TAIPEI.2014.6964374.

McGill, P.R., Sherman, A.D., Hobson, B.W., Henthorn, R.G., Chase, A.C., and Smith, K.L. (2007) Initial deployments of the Rover, an autonomous bottom-transecting instrument platform for long-term measurements in deep benthic environments. In OCEANS 2007, IEEE, Piscataway, NJ, doi: 10.1109/OCEANS.2007.4449315.

McKay, C.P., Anbar, A.D., Porco, C., and Tsou, P. (2014) Follow the plume: the habitability of Enceladus. Astrobiology 14:352-355.

McPhail, S.D. and Pebody, M. (2009) Range-only positioning of a deep-diving autonomous underwater vehicle from a surface ship. IEEE Journal of Oceanic Engineering 34:669-677.

McPhail, S.D., Furlong, M.E., Pebody, M., Perrett, J.R., Stevenson, P., Webb, A., and White, D. (2009) Exploring beneath the PIG Ice Shelf with the Autosub3 AUV. In OCEANS 2009-EUROPE, IEEE, Piscataway, NJ, doi:10.1109/ OCEANSE.2009.5278170.

Menon, C., Broschart, M., and Lan, N. (2007) Biomimetic and robotics for space application: challenges and emerging technologies. IEEE International Conference on Robotics and Automation - Workshop on Biomimetic Robotics, IEEE, Piscataway, NJ, 8 pp.

Merino, N., Aronson, H.S., Bojanova, D.P., Feyhl-Buska, J., Wong, M.L., Zhang, S., and Giovannelli, D. (2019) Living at the extremes: extremophiles and the limits of life in a planetary context. Front Microbiol 10, doi:10.3389/ fmicb.2019.00780.

Michaud, A.B., Skidmore, M.L., Mitchell, A.C., Vick-Majors, T.J., Barbante, C., Turetta, C., vanGelder, W., and Priscu, J.C. (2016) Solute sources and geochemical processes in Subglacial Lake Whillans, West Antarctica. Geology 44:347-350.

Moeslund, T.B. (2012) Introduction to Video and Image Processing, Springer, London.

Morris, K.J., Bett, B.J., Durden, J.M., Huvenne, V.A.I., Milligan, R., Jones, D.O.B., McPhail, S., Robert, K., Bailey, D.M., and Ruhl, H.A. (2014) A new method for ecological surveying of the abyss using autonomous underwater vehicle photography. Limnol Oceanogr Methods 12:795-809.

Mouy, X., Rountree, R., and Juanes, F. (2018) Cataloging fish sounds in the wild using combined acoustic and video recordings. J Acoust Soc Am 143:333-339.

Munk, W., Worcester, P., and Wunsch, C. (1995) Ocean Acoustic Tomography, Cambridge Monographs on Mechanics, Cambridge University Press, Cambridge, UK.

NASA. (2011, March) Radioisotope Power Systems for space exploration. NASA Facts. Available online at https:// www.jpl.nasa.gov/news/fact_sheets/radioisotope-powersystems.pdf

NASEM. (2018) An Astrobiology Science Strategy for the Search for Life in the Universe, The National Academies Press, Washington, DC.

Neveu, M. and Rhoden, A.R. (2019) Evolution of Saturn's midsized moons. Nat Astron 3:543-552. 
Newman, S.A. (2018) Universal EvoDevo? Biol Theory 13:6768.

Olson, S.L., Jensen, M., and Abbott, D.S. (2019) Oceanographic constraints on exoplanet life. arXiv:1909.02928

Paull, L., Saeedi, S., Seto, M., and Li, H. (2014) AUV navigation and localization: a review. IEEE Journal of Oceanic Engineering 39:131-149.

Paulmier, A. and Ruiz-Pino, D. (2009) Oxygen minimum zones (OMZs) in the modern ocean. Prog Oceanogr 80:113-128.

Peters, J.F. (2017) Foundations of Computer Vision, Springer International Publishing, New York.

Postberg, F., Khawaja, N., Abel, B., Choblet, G., Glein, C.R., Gudipati, M.S., Henderson, B.L., Hsu, H.-W., Kempf, S., Klenner, F., Moragas-Klostermeyer, G., Magee, B., Nölle, L., Perry, M., Reviol, R., Schmidt, J., Srama, R., Stolz, F., Tobie, G., Trieloff, M., and Waite, J.H. (2018) Macromolecular organic compounds from the depths of Enceladus. Nature 558:564-568.

Purser, A., Thomsen, L., Hofbauer, M., Menzel, M., Wagner, H., Chapman, R., Barnes, C., and Best, M. (2013) Temporal and spatial benthic data collection via Internet operated Deep Sea Crawler. Methods in Oceanography 5:1-18.

Ramirez-Llodra, E., Brandt, A., Danovaro, R., De Mol, B., Escobar, E., German, C.R., Levin, L.A., Martinez Arbizu, P., Menot, L., Nuhl-Mortensen, P., Narayanaswamy, B.E., Smith, C.R., Tittersonr, D.P., Tyler P.A., Vanreusel, A., and Vecchione, M. (2010) Deep, diverse and definitively different: unique attributes of the world's largest ecosystem. Biogeosciences 7:2851-2899.

Riser, S.C., Freeland, H.J., Roemmich, D., Wijffels, S., Troisi, A., Belbéoch, M., Gilbert, D., Xu, J., Pouliquen, S., Thresher, A., Le Traon, P., Maze, G., Klein, B., Ravichandran, M., Grant, F., Poulain, P., Suga, T., Lim, B., Sterl, A., Sutton, P., Mork, K.A., Vélez-Belchí, P.J., Ansorge, I., King, B., Turton, J., Baringer, M., and Jayne, S.R. (2016) Fifteen years of ocean observations with the global Argo array. Nat Clim Chang 6:145-153.

Rovira-Navarro, M., Rieutord, M., Gerkema, T., Maas, L.R.M., van der Wal, W., and Vermeersen, B. (2019) Do tidally generated inertial waves heat the subsurface oceans of Europa and Enceladus? Icarus 321:126-140.

Sapienza, P. and Riccobene, G. (2009) High-energy neutrino astronomy. Rivista del Nuovo Cimento 32:12.

Saxena, P., Renaud, J.P., Henning, W.G., Jutzi, M., and Hurford, T. (2018) Relevance of tidal heating on large TNOs. Icarus 302:245-260.

Scholin, C.A., Birch, J., Jensen S., Marin, R., III, Massion, E., Pargett, D., Preston, C., Roman, B., and Ussler, W., III. (2017) The quest to develop ecogenomic sensors: a 25-year history of the Environmental Sample Processor (ESP) as a case study. Oceanography 30:100-113.

Schwieterman, E.W., Kiang, N.Y., Parenteau, M.N., Harman, C.E., DasSarma, S., Fisher, T.M., Arney, G.N., Hartnett, H.E., Reinhard, C.T., Olson, S.L., Meadows, V.S., Cockell, C.S., Walker, S.I., Grenfell, J.L., Hegde, S., Rugheimer, S., Hu, R., and Lyons, T.W. (2018) Exoplanet biosignatures: a review of remotely detectable signs of life. Astrobiology 18:663-708.

Seewald, J.S. (2017) Detecting molecular hydrogen on Enceladus. Science 356:132-133.

Shen, J., Wang, J., Yu, C., Chen, X., Wu, J., Zhao, M., Qu, F., $\mathrm{Xu}, \mathrm{Z}$., Han, J., and Xu, J. (2019) Single LED-based 46-m underwater wireless optical communication enabled by a multi-pixel photon counter with digital output. Opt Commun 438:78-82.
Siegert, M.J. (2018) A 60-year international history of Antarctic subglacial lake exploration. Geol Soc Spec Publ 461:7-21.

Siegert, M.J., Priscu, J.C., Alekhina, I.A., Wadham, J.L., and Lyons, W.B. (2016) Antarctic subglacial lake exploration: first results and future plans. Philos Trans A Math Phys Eng Sci 374, doi:10.1098/rsta.2014.0466.

Skiena, S.S. (2017) The Data Science Design Manual, Springer, New York.

Spears, A., West, M., Meister, M., Buffo, J., Walker, C., Collin, T.R., Howard, A., and Schmidt, B. (2016). Underwater ice in Antarctica: the ICEFIN unmanned underwater vehicle development and deployment. IEEE Robot Autom Mag 23:30-41.

Stanev, E., Grayek, S., Claustre, H., Schmechtig, C., and Poteau, A. (2017) Water intrusions and particle signatures in the Black Sea: a biogeochemical-Argo float investigation. Ocean Dyn 67:1119-1136.

Stone, W.C., Fairfield, N., and Kantor, G. (2005) The DEPTHX project: pioneering technologies for exploration of extraterrestrial aqueous channels [abstract 2206]. In 36th Lunar and Planetary Science Conference, Lunar and Planetary Institute, Houston.

Stone, W.C., Hogan, B., Siegel, V., Lelievre, S., and Flesher, C. (2014) Progress towards an optically powered cryobot. Annals of Glaciology 552-13.

Stone, W., Hogan, B., Siegel, V.L., Howe, T., Howe, S., Harman, J., and Rothhammer, B. (2016) SPINDLE: a 2-Stage nuclear-powered Cryobot for ocean world exploration. $A G U$ Fall Meeting Abstracts. Available online at https:// ui.adsabs.harvard.edu/abs/2016AGUFM.C51E..07S

Stone, W.C., Hogan, B., Siegel, V., Harman, J., Flesher, C., Clark, E., Pradhan, O., Gasiewski, A., Howe, S., and Howe, T. (2018) Laser-powered Cryobots and other methods for penetrating deep ice on ocean worlds. In Outer Solar System: Prospective Energy and Material Resources, edited by V. Badescu and K. Zacny, Springer, New York.

Suseela, Y.V., Narayanaswamy, N., Pratihar, S., and Govindaraju, T. (2018) Far-red fluorescent probes for canonical and non-canonical nucleic acid structures: current progress and future implications. Chem Soc Rev 47:1098-1131.

Talalay, P.G. (2020) Thermal Ice Drilling Technology, Geological Publishing House and Springer Nature, Singapore.

Teodoro, L.A., Elphic, R.C., Davila, A.F., McKay, C., and $\varangle$ AU3 Dartnell, L. (2016) The Enceladus ionizing radiation environment: implications for biomolecules. AGU Fall Meeting Abstracts. Available online at https://ui.adsabs.harvard.edu/ abs/2016AGUFM.P32A..10T/abstract

Thomas, P.C., Tajeddine, R., Tiscareno, M.S., Burns, J.A., Joseph, J., Loredo, T.J., Helfenstein, P., and Porco, C. (2016) Enceladus's measured physical libration requires a global subsurface ocean. Icarus 264:37-47.

Thompson, A.F., Chao, Y., Chien, S., Kinsey, J., Flexas, M.M., Erickson, Z.K., Farrara, J., Fratantoni, D., Branch, A., Chu, S., Troesch, M., Claus, B., and Kepper, J. (2017) Satellites to seafloor: toward fully autonomous ocean sampling. Oceanography 30:160-168.

Thomsen, L., Barnes, C., Best, M., Chapman, R., Pirenne, B., Thomson, R., and Vogt, J. (2012) Ocean circulation promotes methane release from gas hydrate outcrops at the NEPTUNE Canada Barkley Canyon node. Geophys Res Lett 39, doi: 10.1029/2012GL052462.

Thomsen, L., Aguzzi, J., Costa, C., De Leo, F., Ogston, A., and Purser, A. (2017) The oceanic biological pump: rapid carbon transfer to depth at continental margins during winter. $S c i$ Rep 7, doi:10.1038/s41598-017-11075-6. 
AU3 Trask, R.P. and Farrar, J.T. (2018) Near real-time data recovery from oceanographic moorings. In Observing the Oceans in Real Time, edited by R. Venkatesan, A. Tandon, E. D'Asaro, and M. Atmanand, Springer Oceanography, Springer, Cham, pp 263-279.

Troesch, M., Chien, S., Chao, Y., Farrara, J., Girton, J., and Dunlap, J. (2018) Autonomous control of marine floats in the presence of dynamic, uncertain ocean currents. Rob Auton Syst 108:100-114.

Turner, J.T. (2015) Zooplankton faecal pellets, marine snow, phytodetritus and the ocean's biological pump. Prog Oceanogr 130:205-248.

Vallicrosa, G., Ridao, P., Ribas, D., and Palomer, A. (2014) Active range-only beacon localization for AUV homing. In 2014 IEEE/RSJ International Conference on Intelligent Robots and Systems, IEEE, Piscataway, NJ, doi:10.1109/ IROS.2014.6942871.

Villanueva, A., Bressers, S., Tadesse, Y., and Priya, S. (2009) Jellyfish inspired underwater unmanned vehicle. Proc SPIE 7287, doi:10.1117/12.815754.

Wadhams, P., Holfort, J., Hansen, E., and Wilkinson, J.P. (2002) A deep convective chimney in the winter Greenland Sea. Geophys Res Lett 29, doi:10.1029/2001GL014306.

Wang, J., Shi, W., Xu, L., Zhou, L., Niu, Q., and Liu, J. (2017) Design of optical-acoustic hybrid underwater wireless sensor network. Journal of Network and Computer Applications 92: $59-67$.

Wedler, A., Hellerer, M., Rebele, B., Gmeiner, H., Vodermayer, B., Bellmann, T., Barthelmes, S., Rosta, R., Lange, C., Witte, L., Schmitz, N., Knapmeyer, M., Czeluschke, A., Thomsen, L., Waldmann, C., Flögel, S., Wilde, M., and Takei, Y. (2015) ROBEX: components and methods for the planetary exploration demonstration mission. In $13^{\text {th }}$ Symposium on Advanced Space Technologies in Robotics and Automation (ASTRA), 10-13 May 2015. Noordwijk, The Netherlands.

Wehde, H., Thomsen, L., Pfannkuche, O., Albiez, J., Flögel, S., Godø, O.R., Torkelsen, T., Valencia, J., Rodriguez, E., Lopez, V., Marini, S., Grimsbø, E., Zhang, G., and Aguzzi, J. (2019). A flexible autonomous bottom resident infrastructure for bentho-pelagic monitoring. In IMEKO TC-19 International Workshop on Metrology for the Sea.

Weiss, P., Yung, K.L., Ng, T.C., Kömle, N.I., Kargl, G., and Kaufmann, E. (2008) Study of a thermal drill head for the exploration of subsurface planetary ice layers. Planet Space Sci 56:1280-1292.

White, C.F., Lin, Y., Clark, C.M., and Lowe, C.G. (2016) Human vs robot: comparing the viability and utility of autonomous underwater vehicles for the acoustic telemetry tracking of marine organisms. J Exp Mar Bio Ecol 485:112118.

Widder, E.A. (2010) Bioluminescence in the ocean: origins of biological, chemical, and ecological diversity. Science 328: 704-708.

Wirtz, M., Hildebrandt, M., and Gaudig, C. (2012) Design and test of a robust docking system for hovering AUVs. In 2012 Oceans, IEEE, Piscataway, NJ, doi:10.1109/OCEANS.2012 .6404975 .

Wollschlager, J., Voß, D., Zielinsky, O., and Petersen, W. (2016) In situ observations of biological and environmental parameters by means of optics development of nextgeneration ocean sensors with special focus on an integrating cavity approach. IEEE Journal of Oceanic Engineering 41: 753-762.
Wynn, R.B., Huvenne, V.A.I., Le Bas, T.P., Murton, B.J., Connelly, D.P., Bett, B.J., Ruhl, H.A., Morris, K.J., Peakall, J., Parsons, D.R., Sumner, E.J., Darby, S.E., Dorrell, R.M., and Hunt, J.E. (2014) Autonomous underwater vehicles (AUVs): their past, present and future contributions to the advancement of marine geoscience. Mar Geol 352:451-468. Yoerger, D., Govindarajan, A., Llopiz, J., Wiebe, P.H., Howland, J.C., German, C.R., Robison, B.H., Katija, K., and Rock, S. (2016) Mesobot: a new class of robot for investigating the ocean's interior. AGU Fall Meeting Abstracts. Available online at https://ui.adsabs.harvard.edu/abs/ 2016AGUOSIS14A2298Y/abstract

Zhang, Y., Bellingham, J.G., Godin, M.A., and Ryan, J.P. (2012) Using an autonomous underwater vehicle to track the thermocline based on peak-gradient detection. Journal of Oceanic Engineering 37:544-553.

Zhang, Y., Bellingham, J.G., Ryan, J.P., Kieft, B., and Stanway, M.J. (2016) Autonomous four-dimensional mapping and tracking of a coastal upwelling front by an autonomous underwater vehicle. Journal of Field Robotics 33:67-81.

Zhang, Y., Ryan, J.P., Kieft, B., Hobson, B.W., McEwen, R.S. Godin, M.A., Harvey, J.B., Barone, B., Bellingham, J.G., Birch, J.M., Scholin, C.A., and Chavez F.P. (2019) Targeted sampling by autonomous underwater vehicles. Front Mar Sci 6, doi:10.3389/fmars.2019.00415.

Zhao, J., Meng, J., Zhang, H., and Wan, S. (2017) Comprehensive detection of gas plumes from multibeam water column images with minimization of noise interferences. Sensors (Basel) 17, doi:10.3390/s17122755.

Zuo, M., Xu, G., Xiang, X., Yu, C., and Cheng, Y. (2015) Design of a newly developed hybrid underwater robotic vehicle [ISOPE-I-15-851]. In 25th International Ocean and Polar Engineering Conference (ISOPE), International Society of Offshore and Polar Engineers, Mountain View, CA.

Address correspondence to: Jacopo Aguzzi

Instituto de Ciencias del Mar (ICM-CSIC) Recursos Marinos Renovables Paseo Maritimo de la Barceloneta 37-49 Barcelona Catalan Country 08003 Spain

E-mail: jaguzzi@icm.csic.es

Submitted 15 June 2019

Accepted 3 February 2020 Associate Editor: Lewis Dartnell

$\begin{aligned} & \quad \text { Abbreviations Used } \\ & \text { AUVs }=\text { autonomous underwater vehicles } \\ & \text { BRUIE }=\text { Buoyant Rover for Under-Ice Exploration } \\ & \text { CTD }=\text { Conductivity-Temperature-Density } \\ & \text { eDNA }=\text { environmental DNA } \\ & \text { eRNA }=\text { environmental RNA } \\ & \text { eXNA }=\text { xeno-nucleic acids } \\ & \text { LOC }=\text { Lab-on-a-Chip } \\ & \text { MBES }=\text { multibeam echo sounders } \\ & \text { PAM }=\text { passive acoustic monitoring } \\ & \text { PMTs }=\text { photomultiplier tubes }\end{aligned}$




\section{AUTHOR QUERY FOR AST-2019-2129-VER9-AGUZZI_1P}

AU1: Konstantinidis et al. (2013) and Reisen et al. (2016) are not found in the reference list. Please reconcile.

AU2: Please spell out HD.

AU3: The following are not found in the text: Aguzzi et al. (2012), Godø et al. (2014), Liu et al. (2014), Teodoro et al. (2016), Trask and Farrar (2018). Please reconcile.

AU4: Update reference, if available.

AU5: Please add the abstract number.

AU6: Please also define AWAC and HP in the table footnote. 